\title{
新型三甲氧基苯基喹啉衍生物的设计、合成及抗肿瘤活性研究
}

\author{
吴博文 ${ }^{\dagger}, a, c$ 崔金金金埕 ${ }^{\dagger}, c$ 朱 挺 ${ }^{a, c}$ 王胜辉 $b$ 陆超凡 $b$ \\ 王金杰 ${ }^{a, c}$ 党贺祥 $a, c$ 张赛扬 $*, a, b, d$ \\ 丁丽娜*,a,c 金成允*,a,c \\ $\left({ }^{a}\right.$ 新药创制与药物安全性评价河南省协同创新中心 郑州 450001) \\ ( ${ }^{b}$ 郑州大学基础医学院 郑州 450001) \\ ( 教育部药物制备关键技术重点实验室 郑州 450001) \\ ( 郑州大学河南省先进技术研究院 郑州 450001)
}

\begin{abstract}
摘要 为了寻找新型高效抗肿瘤候选药物, 设计并合成了一系列新型三甲氧基苯基一喹啉杂合体, 并评估了目标化合 物对三种不同肿瘤细胞 EC-109(人食管癌细胞), PC-3(人前列腺癌细胞)和 MGC-803(人胃癌细胞)的抗增殖活性. 结果表 明 $N$-(3-(氯甲基)芐基)-3,4,5-三甲氧基- $N$-(喹啉-8-基)苯甲酰胺(12j)对 PC-3 细胞具有良好的抗增殖活性, $\mathrm{IC}_{50}$ 值为 9.23 $\mu \mathrm{mol} / \mathrm{L}$. 同时, 化合物 $\mathbf{2} \mathbf{j}$ 抑制 PC-3 细胞增殖和克隆形成. 进一步机制研究表明, 化合物 $\mathbf{1 2 j}$ 可以将 PC-3 细胞阻滞在 G2/M 期，并通过激活内源性和外源性调亡途径诱导细胞调亡.
\end{abstract}

关键词＼cjkstart喹啉; 三甲氧基苯基; 抗肿瘤活性; 细胞周期阻滞; 调亡

\section{Design, Synthesis and Anticancer Activity Studies of Novel Trimethoxyphenyl-quinoline Derivatives}

\author{
Wu, Bowen ${ }^{\dagger, a, c} \quad$ Cui, Xinxin ${ }^{\dagger, a, c} \quad$ Zhu, Ting ${ }^{a, c}$ \\ Wang, Jinjie ${ }^{a, c} \quad$ Dang, Hexiang ${ }^{a, c}$ \\ Wang, Shenghui ${ }^{b}$ \\ Lu, Chaofan ${ }^{b}$ \\ Ding, Li'na*,a,c Jin, Chengyun ${ }^{*, a, c}$ \\ $\left({ }^{a}\right.$ Collaborative Innovation Center of New Drug Research and Safety Evaluation, Henan Province, Zhengzhou 450001) \\ ( ${ }^{b}$ School of Basic Medical Sciences, Zhengzhou University, Zhengzhou 450001) \\ ( ${ }^{c}$ Key Laboratory of Advanced Drug Preparation Technologies, Ministry of Education, Zhengzhou 450001) \\ ( ${ }^{c}$ Henan Institute of Advanced Technology, Zhengzhou University, Zhengzhou 450001)
}

\begin{abstract}
With the expectation to find out novel and effective anti-tumor agents, a series of novel trimethoxyphenylquinoline hybrids were designed, synthesized and evaluated for antiproliferative activity against three human cancer cell lines (EC-109, human esophageal cancer cells; PC-3, human prostate cancer cells; MGC-803, human gastric cancer cells). $N$-(3(Chloromethyl)benzyl)-3,4,5-trimethoxy- $N$-(quinolin-8-yl)benzamide (12j) showed the most potent antitumor activity against PC-3 cells with $\mathrm{IC}_{50}$ value of $9.23 \mu \mathrm{mol} / \mathrm{L}$. Meanwhile, compound $\mathbf{1 2} \mathbf{j}$ inhibited the cell viability and colony formation of PC-3 cells. Further mechanism studies revealed that compound $\mathbf{1 2} \mathbf{j}$ could arrest PC-3 cells in G2/M phase and induce cell apoptosis via activating intrinsic and extrinsic apoptosis pathway.

Keywords quinoline; trimethoxyphenyl; anticancer; cell cycle arrest; apoptosis
\end{abstract}

\footnotetext{
* Corresponding authors. E-mail: saiyangz@zzu.edu.cn; dinglina123@126.com; cyjin@zzu.edu.cn Received September 10, 2019; revised November 21, 2019; published online December 11, 2019. Project supported by the National Natural Science Foundation of China (Nos. 81703541, 81673322) and the China Postdoctoral Science Foundation (No. 2018M632812).

国家自然科学基金(Nos. 81703541, 81673322)和中国博士后科学基金(No. 2018M632812)资助项目.

†共同第一作者(These authors contributed equally to this work).
} 


\section{Introduction}

According to statistics from the International Agency for Research on Cancer in 2018, cancer is expected to rank as one of the leading cause of death and the single most important barrier to increase life expectancy in the 21 st century ${ }^{[1]}$. Although there have some progresses in the treatment and prevention of cancers, successful treatments of cancer remain a challenge. ${ }^{[1 \sim 3]}$ Therefore, there is still an urgent need to develop more efficient and safer antitumor agents.

$\mathrm{N}$-Containing heterocycles play a vital role in the design of medicinal chemical structures. ${ }^{[4 \sim 9]}$ Among them, quinoline and its derivatives have been reported to display broad biological activities such as anticancer, ${ }^{[4 \sim 7]}$ antibacterial, ${ }^{[8,9]}$ anti-HIV, ${ }^{[10,11]}$ anti-inflammation ${ }^{[12]}$ and so on. In recent years, many quinoline-based protein kinase inhibitors have been approved for clinical application by food and drug administration (FDA), such as anlotinib ${ }^{[13]}$, and lenvatinib $^{[14]}$ (Figure 1). Quinoline scaffold plays an important role in anticancer drug development as their derivatives have shown excellent results. ${ }^{[15 \sim 19]}$ What is more, 8-substituted quinolines and their derivatives represent excellent scaffolds in antitumor agents. 8-Hydroxyquinoline (1) has inhibitory effects on relaxation of supercoiled plasmid DNA by suppressing the topoisomerase I enzyme and exhibits moderate antitumor activity against HeLa cell lines with $\mathrm{IC}_{50}$ value of $7.5 \mu \mathrm{mol} / \mathrm{L} .^{[20]}$ Compound 2 showed potent inhibitory activity against VEGFR-2 kinase and HUVEC with $\mathrm{IC}_{50}$ values of 3.8 and $5.5 \mathrm{nmol} / \mathrm{L}$, respectively. ${ }^{[21]}$ Compound $\mathbf{3}$ is a novel HSP90 inhibitor and demonstrates consistent activities in both FP and WB assays with low micromolar activities $(1 \mu \mathrm{mol} / \mathrm{L}) .{ }^{[22]}$ Based on the above findings mentioned, the 8 -aminoquinoline scaffold is chosen as a core for designing novel derivatives in this work (Figure 1).

Meanwhile, many trimethoxyphenyl (TMP)-based derivatives have been discovered as potential anticancer agents $^{[23 \sim 25]}$ such as CA-4, ${ }^{[26]}$ compounds $4^{[27]}$ and $\mathbf{5}^{[28]}$ (Figure 2). Summaries of SAR of compounds 4 and 5 indicate that trimethoxyphenyl (TMP) moiety is essential for the anticancer activity. Recently, the tertiary amide fragments are frequently utilized to design novel anticancer
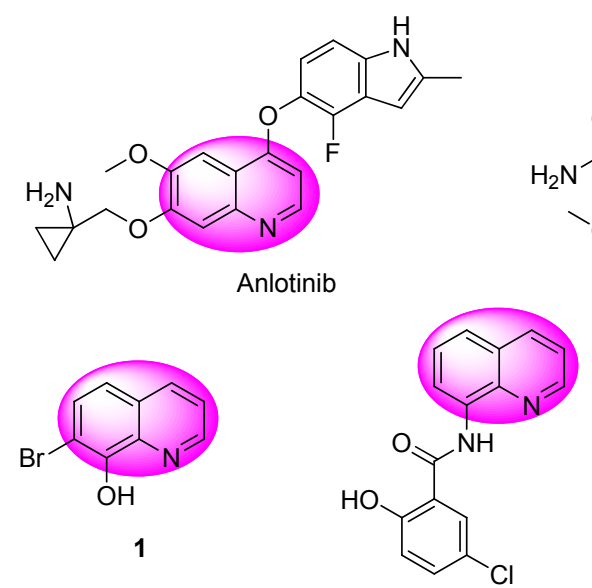

2
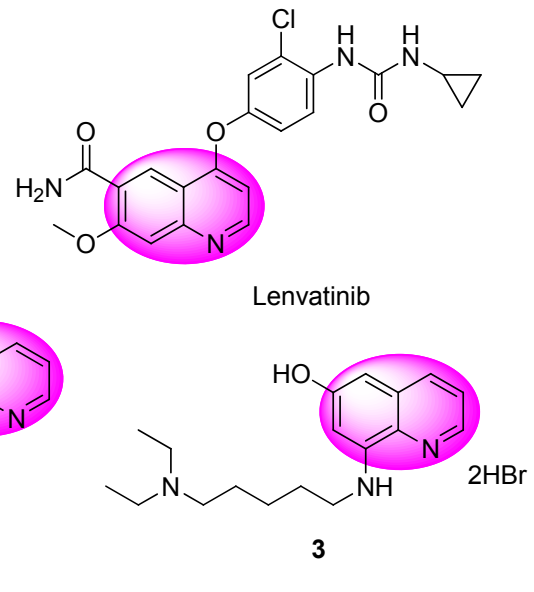$$
\text { . }
$$

Figure 1 Structures of quinoline derivatives previously reported

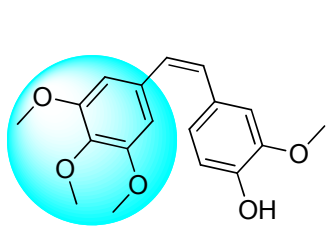

CA-4

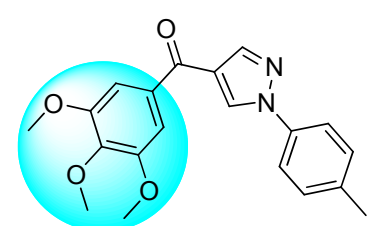

4<smiles>COc1ccc2[nH]cc(/C=C(\C)C(=O)c3cc4c(OC)c(c3)OCCOCCCCO4)c2c1</smiles><smiles>CCCCN1CCC(N(Cc2ccccc2)C(=O)Nc2ccc(Cl)c(Cl)c2)CC1</smiles>

Figure 2 Structures of TMP containing compounds as antitumor agents previously reported and tertiary amide compounds as antitumor agents previously reported 
agents to enhance the biological efficacy. ${ }^{[29 \sim 33]}$ Compound $\mathbf{6}$ as a potent inhibitor of Clk 1 and Clk 4 could trigger the depletion of EGFR and p70S6 kinases. ${ }^{[29]}$ Compound 7 regulated DCN1-mediated cullin neddylation and DCN1UBE2M protein-protein interaction on squamous cell carcinoma cell lines. ${ }^{[30]}$ Tertiary amide 8 containing 3,4,5trimethoxyphenyl fragment exhibited the potent antiproliferative activity against MGC- 803 cell lines with $\mathrm{IC}_{50}$ value of $0.45 \mu \mathrm{mol} / \mathrm{L} .^{[33]}$

As the continuation of our studies on the development of antitumor agents and inspired by the results of the above studies, the amide backbone was linked to trimethoxyphenyl group and quinoline scaffold by the principle of molecular hybridization strategy. Accordingly, a series of trimethoxyphenyl-quinoline hybrids and their activity against three selected cancer cell lines were reported in this work (Figure 3).

\section{Results and discussion}

\subsection{Chemistry}

All the target compounds $\mathbf{1 2 a} \sim \mathbf{1 2 0}$ were synthesized according to Scheme 1. Firstly, compounds 10a $\sim \mathbf{1 0 0}$ were prepared by the reaction of 8 -aminoquinoline (9) with substituted chloromethyl aromatic ring compounds in the presence of $\mathrm{K}_{2} \mathrm{CO}_{3}$ in $N, N$-dimethylformamide (DMF) at room temperature. Then, compounds $10 \mathbf{1 0 a} \sim \mathbf{1 0 0}$ reacted with 3,4,5-trimethoxybenzoyl chloride (11) to obtain compounds $12 \mathbf{a} \sim \mathbf{1 2 0}$ in the presence of triethylamine (TEA) in dichloromethane (DCM) at $25{ }^{\circ} \mathrm{C}$ for $2 \mathrm{~h}$. Finally, the structures of compounds $12 \mathbf{a} \sim \mathbf{1 2 0}$ were fully characterized by ${ }^{1} \mathrm{H}$ NMR, ${ }^{13} \mathrm{C}$ NMR and ESI-MS.

\subsection{Antitumor activity}

All compounds 12a $\sim \mathbf{1 2 0}$ were evaluated for their antitumor activity against three human cancer cell lines (EC-109, PC-3, and MGC-803) using 3-(4,5-dimethylthiazol-2-yl)-2,5-diphenyltetrazolium bromide (MTT) assay method and the anti-tumor drug 5-fluorouracil as a positive control drug. The results are summarized in Tables 1 and 2. Among them, compound 12j showed potential antitumor activity against PC-3 cells and MGC-803 cells with $\mathrm{IC}_{50}$ values of 9.23 and $12.42 \mu \mathrm{mol} / \mathrm{L}$, respectively.

From the antitumor activity results of compounds $\mathbf{1 2 a} \sim$ 12k in Table 1, some of compounds exhibited moderate activity against three human cancer cell lines. The potency of the compounds varies with respect to substitutions on the simple phenyl ring. Among them, $\mathbf{1 2} \mathbf{j}$ showed potential antitumor activity against three cell lines (EC-109, PC-3 and MGC-803) with $\mathrm{IC}_{50}$ values of $18.09 \pm 1.09,9.23 \pm$ 0.81 and $12.46 \pm 0.32 \mu \mathrm{mol} / \mathrm{L}$, respectively. What's more,

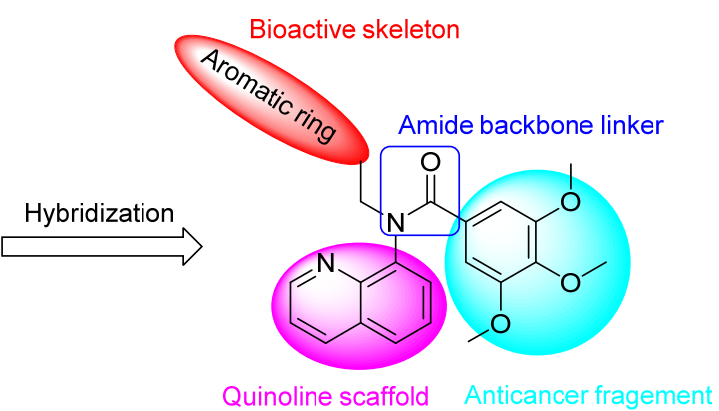

Figure 3 Design of trimethoxyphenyl-quinoline derivatives via molecular hybridization

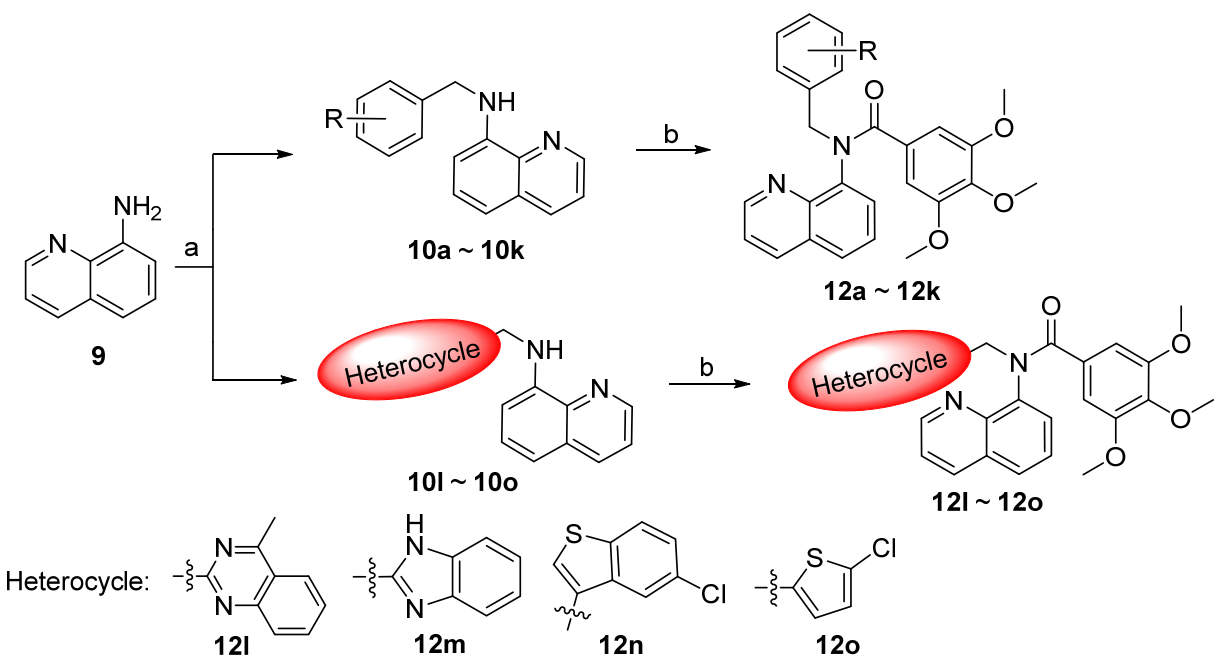

Reagents and conditions: (a) substituted chloromethyl aromatic ring compounds, $\mathrm{K}_{2} \mathrm{CO}_{3}$, DMF, r.t.; (b) 3,4,5-trimethoxybenzoyl chloride, TEA, DCM, r.t.

Scheme 1 Synthesis of target compounds 12a $\sim 120$ 
Table 1 Antitumor activity of compounds $\mathbf{1 2 a} \sim \mathbf{1 2 k}$ against three human cancer cell lines (EC-109, PC-3, and MGC-803)

\begin{tabular}{clccc}
\hline \multirow{2}{*}{ compd. } & \multicolumn{2}{c}{$\mathrm{R}$} & \multicolumn{3}{c}{$\mathrm{IC}_{50}{ }^{a} /\left(\mu \mathrm{mol} \cdot \mathrm{L}^{-1}\right)$} \\
\cline { 3 - 5 } & & $59.53 \pm 3.22$ & PC-3 & MGC-803 \\
\hline $\mathbf{1 2}$ & $4-\mathrm{F}$ & $23.76 \pm 0.01$ & $32.37 \pm 1.54$ & $52.97 \pm 2.96$ \\
$\mathbf{1 2 b}$ & $4-\mathrm{Cl}$ & $29.81 \pm 1.93$ & $21.72 \pm 1.45$ & $35.54 \pm 1.56$ \\
$\mathbf{1 2 c}$ & $4-\mathrm{Br}$ & $33.77 \pm 2.24$ & $19.64 \pm 0.18$ & $64.01 \pm 13.84$ \\
$\mathbf{1 2 d}$ & $4-\mathrm{CH}_{3}$ & $41.77 \pm 12.24$ & $28.37 \pm 1.34$ & $67.73 \pm 0.96$ \\
$\mathbf{1 2}$ & $4-\mathrm{OCH}_{3}$ & $24.16 \pm 2.21$ & $16.62 \pm 1.82$ & $25.57 \pm 1.40$ \\
$\mathbf{1 2 f}$ & $4-\mathrm{C}\left(\mathrm{CH}_{3}\right)_{3}$ & $56.82 \pm 1.02$ & $48.36 \pm 0.91$ & $18.12 \pm 1.84$ \\
$\mathbf{1 2 g}$ & $3-\mathrm{F}$ & $48.90 \pm 1.81$ & $38.79 \pm 2.49$ & $>80$ \\
$\mathbf{1 2 h}$ & $3-\mathrm{Cl}$ & $>80$ & $32.52 \pm 0.78$ & $>80$ \\
$\mathbf{1 2}$ & $3-\mathrm{CH}_{3}$ & $18.09 \pm 1.09$ & $9.23 \pm 0.81$ & $>80$ \\
$\mathbf{1 2} \mathbf{j}$ & $3-\mathrm{CH}_{2} \mathrm{Cl}$ & $54.99 \pm 4.29$ & $68.22 \pm 7.02$ & $12.41 \pm 0.32$ \\
$\mathbf{1 2 k}$ & $2,4-\mathrm{Cl}_{2}$ & $9.79 \pm 0.17$ & $20.42 \pm 1.83$ & $68.75 \pm 1.86$ \\
$5-\mathrm{Fu}$ & - & & & $21.21 \pm 3.61$ \\
\hline
\end{tabular}

${ }^{a}$ Antitumor activity was assayed by exposure for $48 \mathrm{~h}$.

most of compounds against EC-109 cell lines and MGC803 cell lines displayed weaker activity then PC-3 cell lines. Compound $\mathbf{1 2} \mathbf{j}$ with 3 -chloromethyl group showed the most potent activity against PC-3 cell lines with $\mathrm{IC}_{50}$ value of $9.23 \mu \mathrm{mol} / \mathrm{L}$, which exhibited better activity than compounds $12 \mathrm{~g} \sim \mathbf{1 2} \mathbf{i}$ with electron-donating groups and electron-withdrawing groups at the 3-position of phenyl ring. The relationships between the halogen substituents and the antiproliferative activities against PC-3 cell lines were $4-\mathrm{Br}>4-\mathrm{Cl}>4-\mathrm{F}>3-\mathrm{Cl}>3-\mathrm{F}>2,4-\mathrm{Cl}_{2}$. It could also be found that the relationships between the electron-donating groups and the antiproliferative activities against $\mathrm{PC}-3$ cell lines were $4-\mathrm{C}\left(\mathrm{CH}_{3}\right)_{3}>4-\mathrm{OCH}_{3}>4-\mathrm{CH}_{3}>3-\mathrm{CH}_{3}$. In addition, comparing 12a $\sim 12 \mathrm{c}$ with $\mathbf{1 2 d} \sim \mathbf{1 2 f}$, compounds with electron-donating groups of phenyl showed better activity than compounds with electron-withdrawing groups at the 4-position for the inhibitory activity against PC-3 cells.

In order to complete the structure activity relationships, compounds 12I $\sim$ 120 were synthesized and evaluated for their antiproliferative activity as shown in Table 2. Some of compounds $\mathbf{1 2 l} \sim \mathbf{1 2 0}$ retained the cytotoxic activity but displayed weaker activity against three selected cancer cell lines compared to compound $\mathbf{1 2 \mathbf { j }}$. Furthermore, PC-3 cells were more sensitive to the compounds than EC-109 cells, and MGC-803 cells. Compared compound 12j with compounds $12 \mathrm{I} \sim \mathbf{1 2 0}$, the relationships between phenyl ring and heterocyclic rings, and the antiproliferative activities against PC-3 cells were $\mathbf{1 2} \mathbf{j}>\mathbf{1 2} \mathbf{i}>\mathbf{1 2 m}>\mathbf{1 2 n}>\mathbf{1 2 0}$.

Table 2 In vitro cytotoxicity results of compounds $\mathbf{1 2 I} \sim \mathbf{1 2 0}$ against human cancer cell lines (EC-109, PC-3, and MGC-803)

\begin{tabular}{cccc}
\hline \multirow{2}{*}{ Compd. } & \multicolumn{3}{c}{$\mathrm{IC}_{50}{ }^{a} /\left(\mu \mathrm{mol} \cdot \mathrm{L}^{-1}\right)$} \\
\cline { 2 - 4 } & $\mathrm{EC}-109$ & $\mathrm{PC}-3$ & $\mathrm{MGC}-803$ \\
\hline $\mathbf{1 2 j}$ & $18.09 \pm 1.09$ & $9.23 \pm 0.81$ & $12.41 \pm 0.32$ \\
$\mathbf{1 2 l}$ & $38.19 \pm 1.89$ & $12.35 \pm 0.66$ & $20.18 \pm 1.62$ \\
$\mathbf{1 2 m}$ & $42.45 \pm 2.34$ & $24.16 \pm 1.37$ & $24.46 \pm 2.02$ \\
$\mathbf{1 2 n}$ & $12.09 \pm 1.35$ & $19.26 \pm 1.82$ & $18.57 \pm 1.57$ \\
$\mathbf{1 2 0}$ & $47.38 \pm 2.45$ & $32.12 \pm 1.27$ & $46.17 \pm 2.82$ \\
$5-\mathrm{Fu}$ & $9.79 \pm 0.17$ & $20.42 \pm 1.83$ & $21.21 \pm 3.61$ \\
\hline
\end{tabular}

${ }^{a}$ Antiproliferative activity was assayed by exposure for $48 \mathrm{~h}$.

\subsection{Evaluation of biological activity}

Compound $\mathbf{1 2} \mathbf{j}$ was chosen to further evaluate its possible anticancer mechanism of action against PC-3 cell based on the above results. We firstly investigated the impacts of compound $\mathbf{1 2} \mathbf{j}$ on cells viability in PC-3 cells by MTT assay. As shown in Figure 4, after treatment with compound $\mathbf{1 2} \mathbf{j}$ for $48 \mathrm{~h}$, the cell viability was inhibited in a dosedependent manner with an $\mathrm{IC}_{50}$ value of $9.23 \mu \mathrm{mol} / \mathrm{L}$. Then, the effect of compound $\mathbf{1 2} \mathbf{j}$ on the cell proliferation was evaluated by colony formation assay. As shown in Figure 5 , compound $\mathbf{1 2} \mathbf{j}$ inhibited the proliferation of PC-3 cells in a dose-dependent manner after a $7 \mathrm{~d}$ treatment with different concentrations of compound $\mathbf{1 2} \mathbf{j}$. These results suggested that compound $\mathbf{1 2} \mathbf{j}$ inhibited cell viability and proliferation in a dose-dependent manner.

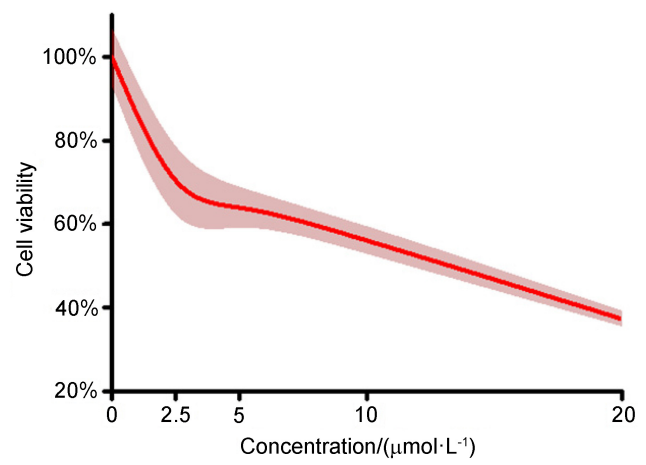

Figure 4 Cell viability of PC-3 cells that were treated with different concentrations of compound $\mathbf{1 2} \mathbf{j}$ for $48 \mathrm{~h}$

To explore the detail cytotoxic effects of $\mathbf{1 2} \mathbf{j}$ on PC-3 cells, the activity inducing cell cycle arrestment was then to detect. After $48 \mathrm{~h}$ treatment with compound $\mathbf{1 2 j}, \mathrm{PC}-3$ cells were arrested in G2/M phase (Figure 6), and the G2 phase related protein CyclinB1 was down regulated (Figure 7). Then, the apoptosis induction of compound $\mathbf{1 2} \mathbf{j}$ against PC-3 cells was next investigated. After $48 \mathrm{~h}$ treatment with different concentrations of compound $\mathbf{1 2} \mathbf{j}$, the apoptosis rate was elevated to about $40 \%$ with high dose treatment group of compounds $\mathbf{1 2} \mathbf{j}$ (Figure 8). The apoptosis related proteins were detected next. The results in Fig- 


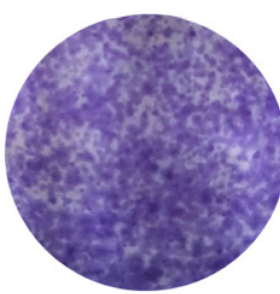

$0 \mu \mathrm{mol} / \mathrm{L}$

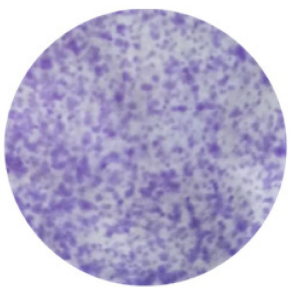

$10 \mu \mathrm{mol} / \mathrm{L}$

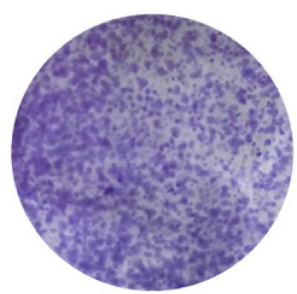

$5 \mu \mathrm{mol} / \mathrm{L}$

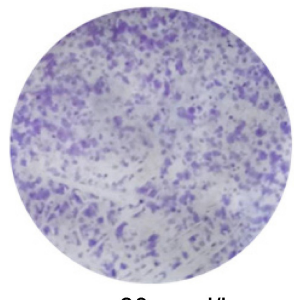

$20 \mu \mathrm{mol} / \mathrm{L}$
Figure 5 Colony formatting analysis

PC-3 cells were treated with different concentrations of compound $\mathbf{1 2} \mathbf{j}$ for $7 \mathrm{~d}$

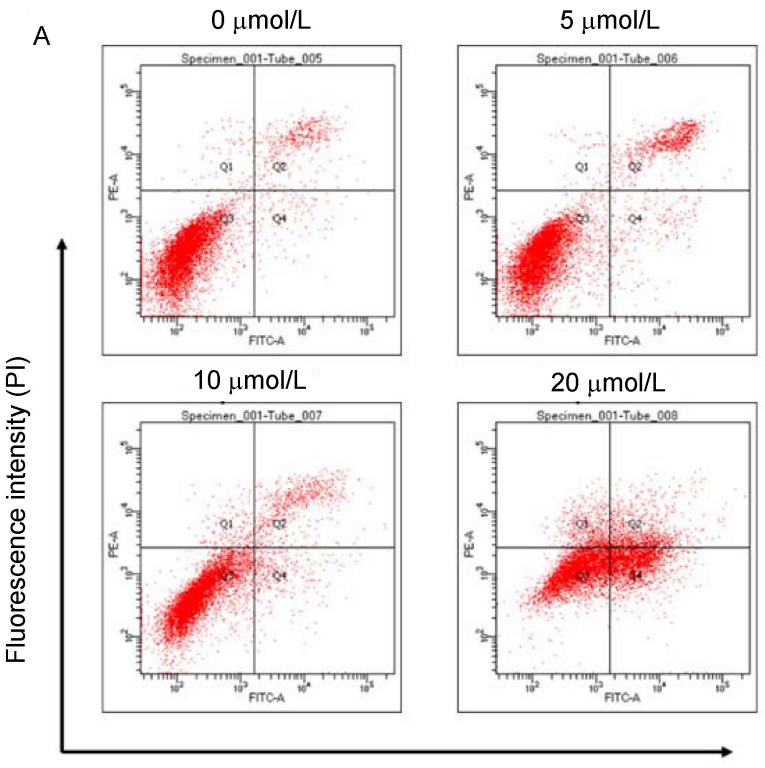

Fluorescence intensity (Annexin V-FITC)

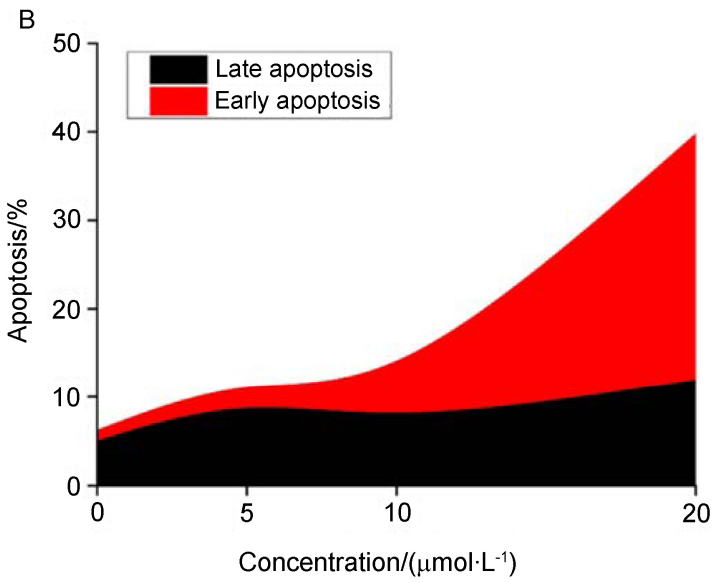

Figure 6 Cell apoptosis induction of compound $\mathbf{1 2 j}$ after 48 hours treatment with different concentrations of compound $\mathbf{1 2} \mathbf{j}$

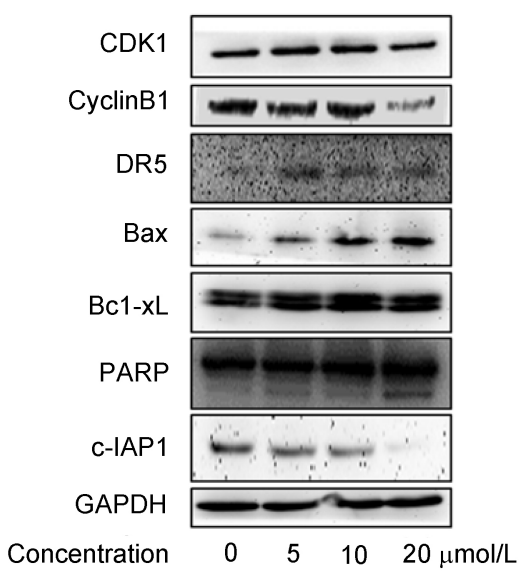

Figure 7 Cell cycle or cell apoptosis related protein levels, PC3 cells were treated with different concentrations of compound $\mathbf{1 2 j}$ for $48 \mathrm{~h}$
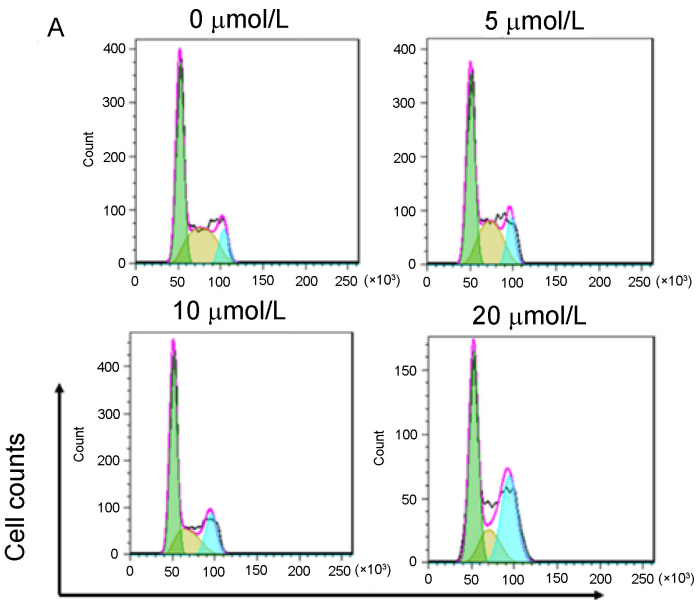

Fluorescence intensity (PI)

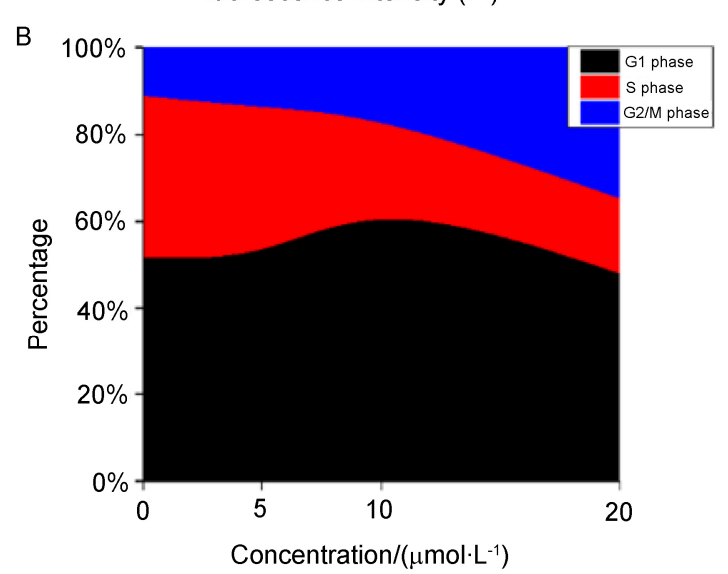

Figure 8 Cell cycle arrestment of compound $\mathbf{1 2} \mathbf{j}$ after $48 \mathrm{~h}$ treatment with different concentrations of compound $\mathbf{1 2} \mathbf{j}$

ure 7 showed that the apoptosis related proteins DR5 and Bax were up-regulated. The anti-apoptosis protein c-IAP1 was down-regulated while Bcl-xL showed no significant change. What's more, apoptosis biomarker PARP was also cleaved (Figure 7). These proteins were involved in both intrinsic and extrinsic apoptosis pathway. Therefore, these results suggested compound $\mathbf{1 2} \mathbf{j}$ arrested PC-3 in G2/M 
phase and induced apoptosis via extrinsic and intrinsic apoptosis pathways.

\section{Conclusions}

In conclusion, a series of novel trimethoxyphenyl-quinoline derivatives were synthesized and evaluated for their antitumor activity against EC-109 cell lines, PC-3 cell lines and MGC-803 cell lines using MTT assay. These chemical structures were characterized by NMR and ESI-MS spectroscopic methods. Among all the tested compounds, compound $\mathbf{1 2} \mathbf{j}$ possessed the best antitumor ability with $\mathrm{IC}_{50}$ value of $9.23 \mu \mathrm{mol} / \mathrm{L}$ against PC-3 cells. Further mechanism studies suggested that compound $\mathbf{1 2} \mathbf{j}$ inhibited the cell viability and cell proliferation of PC-3 cells in a dose-dependent manner. Compound $\mathbf{1 2} \mathbf{j}$ arrested PC-3 cells in G2/M phase and induced cell apoptosis via activating intrinsic and extrinsic apoptosis pathway. Therefore, these results suggested that trimethoxyphenylquinoline hybrids might be considered as potential anticancer agents for further structural modifications and worth a further research.

\section{Experimental}

\subsection{Materials}

All commercial materials were used without further purification. TLC analysis was carried out on silica gel plates GF254 (Qingdao Haiyang Chemical, China). Silica gel chromatography was carried out on $200 \sim 300$ mesh gel. Anhydrous solvents and reagents were dried by routine protocols. Melting points were determined on an X-5 micromelting apparatus and are uncorrected. ${ }^{1} \mathrm{H}$ NMR and ${ }^{13} \mathrm{C}$ NMR spectra were recorded on a Bruker $400 \mathrm{MHz}$ and $100 \mathrm{MHz}$ spectrometer, respectively. Electrospray ionization mass spectrometries of all derivatives were recorded on a Waters Micromass Q-T of Micromass spectrometer by electrospray ionization (ESI).

\subsection{Synthesis}

\subsubsection{Synthesis of compounds $\mathbf{1 0 a} \sim \mathbf{1 0 0}$}

A solution of compound 9, substituted benzyl halides (1.2 equiv.) and anhydrous potassium carbonate (3.0 equiv.) were added into DMF $(5 \mathrm{~mL})$, and then the mixture was stirred at room temperature for $6 \mathrm{~h}$. After completion of the reaction (monitored by thin-layer chromatography (TLC)), water was added and the product was extracted by using ethyl acetate three times. The combined organic phases were washed with saturated $\mathrm{NaCl}$ solution, dried over anhydrous $\mathrm{MgSO}_{4}$ and evaporated to give the products. The crude residue was purified with column chromatography to obtain compounds $\mathbf{1 0 a} \sim \mathbf{1 0 0}$.

$N$-(4-Fluorobenzyl)quinolin-8-amine (10a): Yellow liquid, yield 58\%. ${ }^{1} \mathrm{H}$ NMR (400 MHz, DMSO- $d_{6}$ ) $\delta: 8.76$ (dd, $J=4.1,1.6 \mathrm{~Hz}, 1 \mathrm{H}), 8.20$ (dd, $J=8.3,1.6 \mathrm{~Hz}, 1 \mathrm{H})$, $7.50(\mathrm{dd}, J=8.3,4.2 \mathrm{~Hz}, 1 \mathrm{H}), 7.44(\mathrm{dd}, J=8.4,5.7 \mathrm{~Hz}$, 2H), 7.29 (t, $J=7.9 \mathrm{~Hz}, 1 \mathrm{H}), 7.21 \sim 7.09(\mathrm{~m}, 3 \mathrm{H}), 7.06(\mathrm{~d}$, $J=8.0 \mathrm{~Hz}, 1 \mathrm{H}), 6.57(\mathrm{~d}, J=7.5 \mathrm{~Hz}, 1 \mathrm{H}), 4.53(\mathrm{~d}, J=6.3$
$\mathrm{Hz}, 2 \mathrm{H}) ;{ }^{13} \mathrm{C}$ NMR $\left(100 \mathrm{MHz}, \mathrm{DMSO}-d_{6}\right) \delta: 161.1(\mathrm{~d}, J=$ $240.0 \mathrm{~Hz}), 146.9,144.1,137.5,136.0(\mathrm{~d}, J=3.0 \mathrm{~Hz})$, $135.9,128.9$ (d, $J=8.0 \mathrm{~Hz}), 128.3,127.6,121.7,115.0$ (d, $J=210.0 \mathrm{~Hz}$ ), 113.41, 104.82, 45.36; HRMS (ESI) calcd for $\mathrm{C}_{16} \mathrm{H}_{14} \mathrm{FN}_{2}[\mathrm{M}+\mathrm{H}]^{+}$253.1136, found 253.1131.

$N$-(4-Chlorobenzyl)quinolin-8-amine (10b): Yellow solid, yield 64\%. m.p. 76 78 ${ }^{\circ} \mathrm{C}$; ${ }^{1} \mathrm{H}$ NMR (400 MHz, DMSO- $\left.d_{6}\right) \delta: 8.77(\mathrm{dd}, J=4.2,1.7 \mathrm{~Hz}, 1 \mathrm{H}), 8.21(\mathrm{dd}, J=$ 8.3, 1.6 Hz, 1H), 7.51 (dd, $J=8.3,4.2 \mathrm{~Hz}, 1 \mathrm{H}), 7.43$ (d, $J=8.6 \mathrm{~Hz}, 2 \mathrm{H}), 7.36(\mathrm{~d}, J=8.6 \mathrm{~Hz}, 2 \mathrm{H}), 7.27$ (dd, $J=$ $16.4,8.5 \mathrm{~Hz}, 2 \mathrm{H}), 7.06(\mathrm{dd}, J=8.2,0.9 \mathrm{~Hz}, 1 \mathrm{H}), 6.53$ (dd, $J=7.7,0.9 \mathrm{~Hz}, 1 \mathrm{H}), 4.54(\mathrm{~d}, J=6.1 \mathrm{~Hz}, 2 \mathrm{H}) ;{ }^{13} \mathrm{C} \mathrm{NMR}$ $\left(100 \mathrm{MHz}, \mathrm{DMSO}-d_{6}\right) \delta: 146.9,144.0,139.0,137.6,135.9$, $131.1,128.9,128.3,128.3,127.6,121.7,113.5,104.8$, 45.4; HRMS (ESI) calcd for $\mathrm{C}_{16} \mathrm{H}_{14} \mathrm{ClN}_{2}[\mathrm{M}+\mathrm{H}]^{+}$ 269.0840 , found 269.0836 .

$\mathrm{N}$-(4-Bromobenzyl)quinolin-8-amine (10c): Yellow solid, Yield 66\%. m.p. 92 93 ${ }^{\circ} \mathrm{C} ;{ }^{1} \mathrm{H}$ NMR (400 MHz, DMSO- $\left.d_{6}\right) \delta: 8.83 \sim 8.71(\mathrm{~m}, 1 \mathrm{H}), 8.21(\mathrm{~d}, J=8.3 \mathrm{~Hz}, 1 \mathrm{H})$, $7.55 \sim 7.45(\mathrm{~m}, 3 \mathrm{H}), 7.36(\mathrm{~d}, J=7.9 \mathrm{~Hz}, 2 \mathrm{H}), 7.31 \sim 7.18$ $(\mathrm{m}, 2 \mathrm{H}), 7.06(\mathrm{~d}, J=8.1 \mathrm{~Hz}, 1 \mathrm{H}), 6.52(\mathrm{~d}, J=7.6 \mathrm{~Hz}, 1 \mathrm{H})$, $4.52(\mathrm{~d}, J=6.3 \mathrm{~Hz}, 2 \mathrm{H}) ;{ }^{13} \mathrm{C}$ NMR $\left(100 \mathrm{MHz}, \mathrm{DMSO}-d_{6}\right)$ $\delta: 147.0,144.0,139.5,137.5,135.9,131.2,129.2,128.3$, 127.6, 121.7, 119.6, 113.5, 104.8, 45.4; HRMS (ESI) calcd for $\mathrm{C}_{16} \mathrm{H}_{14} \mathrm{BrN}_{2}[\mathrm{M}+\mathrm{H}]^{+}$313.0335, found 313.0328.

$N$-(4-Methylbenzyl)quinolin-8-amine (10d): Yellow solid, yield 47\%. m.p. 53 55 ${ }^{\circ} \mathrm{C}$; ${ }^{1} \mathrm{H}$ NMR (400 MHz, DMSO- $\left.d_{6}\right) \delta: 8.75(\mathrm{dd}, J=4.1,1.6 \mathrm{~Hz}, 1 \mathrm{H}), 8.20(\mathrm{dd}, J=$ $8.3,1.6 \mathrm{~Hz}, 1 \mathrm{H}), 7.50(\mathrm{dd}, J=8.3,4.2 \mathrm{~Hz}, 1 \mathrm{H}), 7.28(\mathrm{t}, J=$ $7.9 \mathrm{~Hz}, 3 \mathrm{H}), 7.12(\mathrm{~d}, J=7.8 \mathrm{~Hz}, 2 \mathrm{H}), 7.05(\mathrm{~d}, J=8.1 \mathrm{~Hz}$, $2 \mathrm{H}), 6.57$ (d, $J=7.6 \mathrm{~Hz}, 1 \mathrm{H}), 4.49$ (s, 2H), 2.26 (s, 3H); ${ }^{13} \mathrm{C}$ NMR (100 MHz, DMSO) $\delta: 146.9,144.2,137.5$, $136.7,136.0,135.7,128.9,128.3,127.6,127.1,121.7$, 113.3, 104.9, 46.0, 20.6; HRMS (ESI) calcd for $\mathrm{C}_{17} \mathrm{H}_{17} \mathrm{~N}_{2}$ $[\mathrm{M}+\mathrm{H}]^{+}$249.1386, found 249.1382.

$N$-(4-Methoxybenzyl)quinolin-8-amine (10e): Yellow solid, Yield 52\%. m.p. 67 69 ${ }^{\circ} \mathrm{C} ;{ }^{1} \mathrm{H}$ NMR $(400 \mathrm{MHz}$, DMSO- $\left.d_{6}\right) \delta: 8.75(\mathrm{dd}, J=4.1,1.6 \mathrm{~Hz}, 1 \mathrm{H}), 8.20(\mathrm{dd}, J=$ $8.3,1.5 \mathrm{~Hz}, 1 \mathrm{H}), 7.50(\mathrm{dd}, J=8.3,4.2 \mathrm{~Hz}, 1 \mathrm{H}), 7.33(\mathrm{t}, J=$ $7.1 \mathrm{~Hz}, 2 \mathrm{H}), 7.30 \sim 7.24(\mathrm{~m}, 1 \mathrm{H}), 7.09 \sim 6.98(\mathrm{~m}, 2 \mathrm{H}), 6.89$ $(\mathrm{d}, J=8.6 \mathrm{~Hz}, 2 \mathrm{H}), 6.61(\mathrm{~d}, J=7.6 \mathrm{~Hz}, 1 \mathrm{H}), 4.46(\mathrm{~d}, J=$ $5.3 \mathrm{~Hz}, 2 \mathrm{H}), 3.72(\mathrm{~s}, 3 \mathrm{H}) ;{ }^{13} \mathrm{C}$ NMR (100 MHz, DMSO-d $)$ $\delta: 158.2,146.9,144.2,137.5,135.9,131.5,129.1,128.4$, 128.2, 127.6, 121.7, 113.8, 113.6, 113.3, 104.8, 56.0, 45.7; HRMS (ESI) calcd for $\mathrm{C}_{17} \mathrm{H}_{17} \mathrm{~N}_{2} \mathrm{O}[\mathrm{M}+\mathrm{H}]^{+}$265.1335, found 265.1333 .

$N$-(3-Fluorobenzyl)quinolin-8-amine (10g): Yellow liquid, yield $67 \%$. ${ }^{1} \mathrm{H}$ NMR (400 MHz, DMSO- $\left.d_{6}\right) \delta: 8.80$ (dd, $J=4.2,1.7 \mathrm{~Hz}, 1 \mathrm{H}), 8.23$ (dd, $J=8.3,1.6 \mathrm{~Hz}, 1 \mathrm{H}$ ), $7.54(\mathrm{dd}, J=8.3,4.2 \mathrm{~Hz}, 1 \mathrm{H}), 7.38(\mathrm{td}, J=7.9,6.1 \mathrm{~Hz}$, 1H), 7.30 (dd, $J=15.5,7.7 \mathrm{~Hz}, 3 \mathrm{H}), 7.23$ (d, $J=10.2 \mathrm{~Hz}$, $1 \mathrm{H}), 7.12 \sim 7.02(\mathrm{~m}, 2 \mathrm{H}), 6.63 \sim 6.52(\mathrm{~m}, 1 \mathrm{H}), 4.60(\mathrm{~d}, J=$ $6.4 \mathrm{~Hz}, 2 \mathrm{H}) ;{ }^{13} \mathrm{C}$ NMR $\left(100 \mathrm{MHz}, \mathrm{DMSO}-d_{6}\right) \delta: 162.2(\mathrm{~d}$, $J=242.0 \mathrm{~Hz}), 146.8,143.9,143.1(\mathrm{~d}, J=7.0 \mathrm{~Hz}), 137.4$, 135. 8, 130.1 (d, $J=8.0 \mathrm{~Hz}), 128.1,127.4,122.81$ (d, $J=$ $3.0 \mathrm{~Hz}), 121.55,113.3(\mathrm{~d}, J=40.0 \mathrm{~Hz}), 113.37,113.3(\mathrm{~d}$, $J=2.0 \mathrm{~Hz}$ ), 104.7, 45.5; HRMS (ESI) calcd for $\mathrm{C}_{16} \mathrm{H}_{14} \mathrm{FN}_{2}$ 
$[\mathrm{M}+\mathrm{H}]^{+}$253. 1136, found 253. 1135 .

$\mathrm{N}$-(3-Chlorobenzyl)quinolin-8-amine (10h): Yellow liquid, yield 54\%. ${ }^{1} \mathrm{H}$ NMR (400 MHz, DMSO- $\left.d_{6}\right) \delta: 8.78$ (dd, $J=4.1,1.3 \mathrm{~Hz}, 1 \mathrm{H}), 8.21$ (dd, $J=8.3,1.3 \mathrm{~Hz}, 1 \mathrm{H})$, 7.51 (dd, $J=8.2,4.2 \mathrm{~Hz}, 1 \mathrm{H}), 7.46$ (s, 1H), 7.36 (dd, $J=$ 13.0, 7.6 Hz, 2H), 7.29 (dd, $J=14.2,6.4 \mathrm{~Hz}, 3 \mathrm{H}), 7.06$ (d, $J=8.1 \mathrm{~Hz}, 1 \mathrm{H}), 6.55(\mathrm{~d}, J=7.6 \mathrm{~Hz}, 1 \mathrm{H}), 4.56(\mathrm{~d}, J=5.8$ $\mathrm{Hz}, 2 \mathrm{H}) ;{ }^{13} \mathrm{C}$ NMR (100 MHz, DMSO- $\left.d_{6}\right) \delta: 147.0,144.0$, $142.8,137.5,136.0,133.1,130.2,128.3,127.6,126.7$, 126.6, 125.7, 121.7, 113.6, 104.8, 45.5; HRMS (ESI) calcd for $\mathrm{C}_{16} \mathrm{H}_{14} \mathrm{ClN}_{2}[\mathrm{M}+\mathrm{H}]^{+}$269.0840, found 269.0838.

$\mathrm{N}$-(3-Methylbenzyl)quinolin-8-amine (10i): Yellow liquid, yield 51\%. ${ }^{1} \mathrm{H}$ NMR (400 MHz, DMSO- $d_{6}$ ) $\delta: 8.76$ (dd, $J=4.2,1.7 \mathrm{~Hz}, 1 \mathrm{H}), 8.20(\mathrm{dd}, J=8.3,1.6 \mathrm{~Hz}, 1 \mathrm{H})$, 7.50 (dd, $J=8.3,4.2 \mathrm{~Hz}, 1 \mathrm{H}), 7.29$ (t, $J=7.9 \mathrm{~Hz}, 1 \mathrm{H}), 7.23$ $(\mathrm{s}, 1 \mathrm{H}), 7.21 \sim 7.18(\mathrm{~m}, 2 \mathrm{H}), 7.10 \sim 7.01(\mathrm{~m}, 3 \mathrm{H}), 6.62 \sim$ $6.54(\mathrm{~m}, 1 \mathrm{H}), 4.49(\mathrm{~d}, J=6.1 \mathrm{~Hz}, 2 \mathrm{H}), 2.26(\mathrm{~s}, 3 \mathrm{H}) ;{ }^{13} \mathrm{C}$ NMR (100 MHz, DMSO- $\left.d_{6}\right) \delta: 146.9,144.3,139.8,137.5$, $137.4,135.9,128.3,127.7,127.6,127.4,124.2,121.7$, 113.3, 104.8, 46.2, 21.0; HRMS (ESI) calcd for $\mathrm{C}_{17} \mathrm{H}_{17} \mathrm{~N}_{2}$ $[\mathrm{M}+\mathrm{H}]^{+}$249.1386, found 249.1383.

$\mathrm{N}$-(3-(Chloromethyl)benzyl)quinolin-8-amine $\quad(\mathbf{1 0 j})$ : Yellow liquid, yield 65\%. ${ }^{1} \mathrm{H}$ NMR (400 MHz, DMSO- $d_{6}$ ) $\delta: 8.77(\mathrm{dd}, J=4.1,1.6 \mathrm{~Hz}, 1 \mathrm{H}), 8.22(\mathrm{dd}, J=8.3,1.5 \mathrm{~Hz}$, $1 \mathrm{H}), 7.52(\mathrm{dd}, J=8.3,4.2 \mathrm{~Hz}, 1 \mathrm{H}), 7.49(\mathrm{~s}, 1 \mathrm{H}), 7.41 \sim$ $7.26(\mathrm{~m}, 4 \mathrm{H}), 7.06(\mathrm{~d}, J=8.1 \mathrm{~Hz}, 1 \mathrm{H}), 6.57(\mathrm{~d}, J=7.6 \mathrm{~Hz}$, $1 \mathrm{H}), 4.74(\mathrm{~s}, 2 \mathrm{H}), 4.55(\mathrm{~s}, 2 \mathrm{H}) ;{ }^{13} \mathrm{C}$ NMR $(100 \mathrm{MHz}$, DMSO- $\left.d_{6}\right) \delta: 146.7,143.8,140.3,137.7,136.6,128.7$, $128.4,127.8,127.4,127.3,127.1,121.7,113.6,105.3$, 46.2, 46.1; HRMS (ESI) calcd for $\mathrm{C}_{17} \mathrm{H}_{16} \mathrm{ClN}_{2}[\mathrm{M}+\mathrm{H}]^{+}$ 283.0997, found 283.0992.

$\mathrm{N}$-(2,4-Dichlorobenzyl)quinolin-8-amine (10k): White solid, yield 59\%. m.p. 162 163 ${ }^{\circ} \mathrm{C} ;{ }^{1} \mathrm{H}$ NMR (400 MHz, DMSO- $\left.d_{6}\right) \delta: 8.79(\mathrm{~d}, J=2.5 \mathrm{~Hz}, 1 \mathrm{H}), 8.23(\mathrm{~d}, J=8.2 \mathrm{~Hz}$, $1 \mathrm{H}), 7.63(\mathrm{~s}, 1 \mathrm{H}), 7.53$ (dd, $J=8.2,4.1 \mathrm{~Hz}, 1 \mathrm{H}), 7.35$ (s, 2H), $7.28(\mathrm{t}, J=7.7 \mathrm{~Hz}, 2 \mathrm{H}), 7.09(\mathrm{~d}, J=8.1 \mathrm{~Hz}, 1 \mathrm{H}), 6.44$ $(\mathrm{d}, J=7.5 \mathrm{~Hz}, 1 \mathrm{H}), 4.59(\mathrm{~d}, J=5.0 \mathrm{~Hz}, 2 \mathrm{H}) ;{ }^{13} \mathrm{C} \mathrm{NMR}$ $\left(100 \mathrm{MHz}, \mathrm{DMSO}-d_{6}\right) \delta: 147.1,143.7,137.5,136.0,135.8$, $133.1,132.0,129.8,128.7,128.3,127.6,127.3,121.8$, 113.9, 104.7, 43.6; HRMS (ESI) calcd for $\mathrm{C}_{16} \mathrm{H}_{13} \mathrm{Cl}_{2} \mathrm{~N}_{2}$ $[\mathrm{M}+\mathrm{H}]^{+}$303.0450, found 303.0444.

$\mathrm{N}$-((4-Methylquinazolin-2-yl)methyl)quinolin-8-amine (101): Yellow solid, yield 57\%. m.p. $175 \sim 176{ }^{\circ} \mathrm{C} ;{ }^{1} \mathrm{H}$ NMR (400 MHz, DMSO- $\left.d_{6}\right) \delta: 8.85(\mathrm{dd}, J=4.2,1.7 \mathrm{~Hz}$, $1 \mathrm{H}), 8.35 \sim 8.16(\mathrm{~m}, 2 \mathrm{H}), 8.01(\mathrm{~d}, J=1.7 \mathrm{~Hz}, 2 \mathrm{H}), 7.73$ (ddd, $J=8.2,5.7,2.4 \mathrm{~Hz}, 1 \mathrm{H}), 7.54(\mathrm{dd}, J=7.1,2.9 \mathrm{~Hz}$, 2H), 7.39 (t, $J=7.9 \mathrm{~Hz}, 1 \mathrm{H}), 7.20 \sim 7.06(\mathrm{~m}, 1 \mathrm{H}), 6.79$ (d, $J=7.0 \mathrm{~Hz}, 1 \mathrm{H}), 4.79(\mathrm{~d}, J=5.1 \mathrm{~Hz}, 2 \mathrm{H}), 2.96(\mathrm{~s}, 3 \mathrm{H}) ;{ }^{13} \mathrm{C}$ NMR (100 MHz, DMSO- $\left.d_{6}\right) \delta$ : 169.0, 162.1, 148.9, 147.2, $144.0,137.6,135.9,134.3,128.2,127.9,127.8,127.4$, 125.9, 122.6, 121.8, 113.7, 104.9, 48.9, 21.6; HRMS (ESI) calcd for $\mathrm{C}_{19} \mathrm{H}_{17} \mathrm{~N}_{4}[\mathrm{M}+\mathrm{H}]^{+}$301.1448, found 301.1441.

$\mathrm{N}$-((1H-Benzo[d]imidazol-2-yl)methyl)quinolin-8-amine (10m): White solid, yield 68\%. m.p. $180 \sim 181{ }^{\circ} \mathrm{C} ;{ }^{1} \mathrm{H}$ NMR (400 MHz, DMSO- $\left.d_{6}\right) \delta: 12.37$ (s, 1H), 8.82 (dd, $J=4.1,1.6 \mathrm{~Hz}, 1 \mathrm{H}), 8.23(\mathrm{dd}, J=8.3,1.5 \mathrm{~Hz}, 1 \mathrm{H}), 7.52$ (dt, $J=21.4,10.7 \mathrm{~Hz}, 3 \mathrm{H}), 7.31$ (dt, $J=13.4,6.8 \mathrm{~Hz}, 2 \mathrm{H}$ ),
7.14 (ddd, $J=14.9,9.4,5.8 \mathrm{~Hz}, 3 \mathrm{H}), 6.70$ (d, $J=7.4 \mathrm{~Hz}$, $1 \mathrm{H}), 4.77(\mathrm{~d}, J=5.8 \mathrm{~Hz}, 2 \mathrm{H}) ;{ }^{13} \mathrm{C}$ NMR $(100 \mathrm{MHz}$, DMSO- $\left.d_{6}\right) \delta: 153.1,147.1,144.1,137.6,135.9,128.2$, 127.6, 121.8, 121.4, 114.1, 104.9, 41.5; HRMS (ESI) calcd for $\mathrm{C}_{17} \mathrm{H}_{15} \mathrm{~N}_{4}[\mathrm{M}+\mathrm{H}]^{+}$275.1291, found 275.1282.

$N$-((5-Chlorobenzo[b]thiophen-3-yl)methyl)quinolin-8amine (10n): White solid, yield $71 \%$. m.p. $178 \sim 179{ }^{\circ} \mathrm{C}$; ${ }^{1} \mathrm{H}$ NMR (400 MHz, DMSO- $\left.d_{6}\right) \delta: 8.76(\mathrm{~d}, J=2.2 \mathrm{~Hz}$, $1 \mathrm{H}), 8.25$ (s, 1H), 8.20 (d, $J=8.1 \mathrm{~Hz}, 1 \mathrm{H}), 8.01$ (d, $J=8.6$ $\mathrm{Hz}, 1 \mathrm{H}), 7.77$ (s, 1H), 7.50 (dd, $J=8.1,4.1 \mathrm{~Hz}, 1 \mathrm{H}), 7.39$ $(\mathrm{d}, J=8.5 \mathrm{~Hz}, 1 \mathrm{H}), 7.32(\mathrm{t}, J=7.9 \mathrm{~Hz}, 1 \mathrm{H}), 7.26(\mathrm{~s}, 1 \mathrm{H})$, $7.06(\mathrm{~d}, J=8.1 \mathrm{~Hz}, 1 \mathrm{H}), 6.78$ (d, $J=7.6 \mathrm{~Hz}, 1 \mathrm{H}), 4.77$ (d, $J=5.2 \mathrm{~Hz}, 2 \mathrm{H}) ;{ }^{13} \mathrm{C}$ NMR $\left(100 \mathrm{MHz}, \mathrm{DMSO}-d_{6}\right) \delta: 146.9$, $144.2,139.4,138.6,137.5,136.0,133.7,129.4,128.3$, $127.6,126.4,124.5,124.4,121.8,121.7,113.5,104.9$, 40.8; HRMS (ESI) calcd for $\mathrm{C}_{18} \mathrm{H}_{14} \mathrm{ClN}_{2} \mathrm{~S}[\mathrm{M}+\mathrm{H}]$ 325.0561 , found 325.0552 .

$\mathrm{N}$-((5-Chlorothiophen-2-yl)methyl)quinolin-8-amine (10o): Yellow liquid, yield 35\%. ${ }^{1} \mathrm{H}$ NMR (400 MHz, DMSO- $\left.d_{6}\right) \delta: 8.75(\mathrm{dd}, J=4.2,1.6 \mathrm{~Hz}, 1 \mathrm{H}), 8.21(\mathrm{dd}, J=$ $8.3,1.6 \mathrm{~Hz}, 1 \mathrm{H}), 7.50(\mathrm{dd}, J=8.3,4.2 \mathrm{~Hz}, 1 \mathrm{H}), 7.33$ (t, $J=$ $7.9 \mathrm{~Hz}, 1 \mathrm{H}), 7.20(\mathrm{~s}, 1 \mathrm{H}), 7.12 \sim 7.08(\mathrm{~m}, 1 \mathrm{H}), 6.98(\mathrm{~d}, J=$ $3.7 \mathrm{~Hz}, 1 \mathrm{H}), 6.94(\mathrm{~d}, J=3.7 \mathrm{~Hz}, 1 \mathrm{H}), 6.75 \sim 6.69(\mathrm{~m}, 1 \mathrm{H})$, $4.66(\mathrm{~s}, 2 \mathrm{H}) ;{ }^{13} \mathrm{C}$ NMR (100 MHz, DMSO- $\left.d_{6}\right) \delta: 147.1$, $143.8,143.7,137.6,136.0,128.3,127.5,126.4,126.1$, 124.7, 121.7, 114.1, 105.2, 41.8; HRMS (ESI) calcd for $\mathrm{C}_{14} \mathrm{H}_{12} \mathrm{ClN}_{2} \mathrm{~S}[\mathrm{M}+\mathrm{H}]^{+}$275.0404, found 275.0402.

4.2.2 Synthesis of trimethoxyphenyl-quinoline derivatives $12 \mathbf{a} \sim 120$

A solution of compounds $\mathbf{1 0 a} \sim \mathbf{1 0 0}(1.0$ equiv.), 3,4,5-trimethoxybenzoyl chloride (11, 1.2 equiv.) and TEA (3.0 equiv.) were added into DCM $(10 \mathrm{~mL})$. And then the mixture was stirred at room temperature for $2 \mathrm{~h}$. After completion of the reaction (monitored by TLC), the mixture was further purified using column chromatography to afford the pure compounds $12 \mathbf{a} \sim \mathbf{1 2 0}$ in moderate yield.

$N$-(4-Fluorobenzyl)-3,4,5-trimethoxy- $N$-(quinolin-8yl)benzamide (12a): White solid, yield 71\%. m.p. 160 $161{ }^{\circ} \mathrm{C} ;{ }^{1} \mathrm{H}$ NMR (400 MHz, $\mathrm{CDCl}_{3}$ ) $\delta: 8.98$ (d, $J=2.8$ $\mathrm{Hz}, 1 \mathrm{H}), 8.11$ (d, $J=8.1 \mathrm{~Hz}, 1 \mathrm{H}), 7.59$ (d, $J=8.1 \mathrm{~Hz}, 1 \mathrm{H})$, 7.41 (dd, $J=8.2,4.1 \mathrm{~Hz}, 1 \mathrm{H}), 7.14(\mathrm{dd}, J=8.3,5.8 \mathrm{~Hz}$, $3 \mathrm{H}), 6.92 \sim 6.75(\mathrm{~m}, 3 \mathrm{H}), 6.49(\mathrm{~s}, 2 \mathrm{H}), 5.81(\mathrm{~d}, J=12.6$ $\mathrm{Hz}, 1 \mathrm{H}), 4.57$ (dd, $J=49.7,12.5 \mathrm{~Hz}, 1 \mathrm{H}), 3.60$ (s, 3H), $3.30(\mathrm{~s}, 6 \mathrm{H}) ;{ }^{13} \mathrm{C} \mathrm{NMR}\left(100 \mathrm{MHz}, \mathrm{CDCl}_{3}\right) \delta: 170.12,162.1$ $(\mathrm{d}, J=440.0 \mathrm{~Hz}), 151.2,149.5,139.0,138.0,135.6,132.5$ $(\mathrm{d}, J=3.0 \mathrm{~Hz}), 130.5,130.0(\mathrm{~d}, J=8.0 \mathrm{~Hz}), 128.3,126.8$, $125.3,120.7,114.0$ (d, $J=210.0 \mathrm{~Hz}$ ), 104.6, 59.7, 54.6, 51.5; HRMS (ESI) calcd for $\mathrm{C}_{26} \mathrm{H}_{24} \mathrm{FN}_{2} \mathrm{O}_{4}[\mathrm{M}+\mathrm{H}]^{+}$ 447.1715, found 447.1733.

$N$-(4-Chlorobenzyl)-3,4,5-trimethoxy- $N$-(quinolin-8yl)benzamide (12b): White solid, yield 67\%. m.p. 166 $168{ }^{\circ} \mathrm{C} ;{ }^{1} \mathrm{H}$ NMR $\left(400 \mathrm{MHz}, \mathrm{CDCl}_{3}\right) \delta: 8.98$ (d, $J=2.8$ $\mathrm{Hz}, 1 \mathrm{H}), 8.10$ (d, $J=8.1 \mathrm{~Hz}, 1 \mathrm{H}), 7.59$ (d, $J=8.1 \mathrm{~Hz}, 1 \mathrm{H})$, $7.41(\mathrm{dd}, J=8.2,4.1 \mathrm{~Hz}, 1 \mathrm{H}), 7.18 \sim 7.08(\mathrm{~m}, 5 \mathrm{H}), 6.87(\mathrm{t}$, $J=14.7 \mathrm{~Hz}, 1 \mathrm{H}), 6.49(\mathrm{~s}, 2 \mathrm{H}), 5.80(\mathrm{~d}, J=12.3 \mathrm{~Hz}, 1 \mathrm{H})$, $4.63(\mathrm{~d}, J=12.9 \mathrm{~Hz}, 1 \mathrm{H}), 3.60(\mathrm{~s}, 3 \mathrm{H}), 3.30(\mathrm{~s}, 6 \mathrm{H}) ;{ }^{13} \mathrm{C}$ 
NMR $\left(100 \mathrm{MHz}, \mathrm{CDCl}_{3}\right) \delta: 170.1,151.2,149.6,142.8$, $139.0,137.9,135.6,135.2,132.1,130.4,129.9,129.7$, 128.2, 127.3, 126.9, 125.3, 120.7, 104.5, 59.6, 54.6, 51.5; HRMS (ESI) calcd for $\mathrm{C}_{26} \mathrm{H}_{24} \mathrm{ClN}_{2} \mathrm{O}_{4}[\mathrm{M}+\mathrm{H}]^{+} 463.1419$, found 463.1425 .

$N$-(4-Bromobenzyl)-3,4,5-trimethoxy- $N$-(quinolin-8yl)benzamide (12c): White solid, yield 69\%. m.p. 161 $162{ }^{\circ} \mathrm{C} ;{ }^{1} \mathrm{H}$ NMR (400 MHz, $\left.\mathrm{CDCl}_{3}\right) \delta: 8.98$ (dd, $J=4.1$, $1.4 \mathrm{~Hz}, 1 \mathrm{H}), 8.11(\mathrm{~d}, J=8.0 \mathrm{~Hz}, 1 \mathrm{H}), 7.60(\mathrm{~d}, J=7.9 \mathrm{~Hz}$, $1 \mathrm{H}), 7.41(\mathrm{dd}, J=8.3,4.2 \mathrm{~Hz}, 1 \mathrm{H}), 7.31 \sim 7.24(\mathrm{~m}, 2 \mathrm{H})$, 7.15 (t, $J=7.8 \mathrm{~Hz}, 1 \mathrm{H}), 7.07$ (d, $J=8.3 \mathrm{~Hz}, 2 \mathrm{H}), 6.88$ (t, $J=18.3 \mathrm{~Hz}, 1 \mathrm{H}), 6.48$ (s, 2H), $5.78(\mathrm{~d}, J=13.7 \mathrm{~Hz}, 1 \mathrm{H})$, $4.59(\mathrm{t}, J=22.7 \mathrm{~Hz}, 1 \mathrm{H}), 3.60(\mathrm{~s}, 3 \mathrm{H}), 3.30(\mathrm{~s}, 6 \mathrm{H}) ;{ }^{13} \mathrm{C}$ NMR $\left(100 \mathrm{MHz}, \mathrm{CDCl}_{3}\right) \delta: 170.2,151.2,149.6,142.9$, $139.0,138.0,135.8,135.6,130.4,130.3,130.1,129.9$, $128.3,126.9,125.3,120.7,120.3,104.6,59.7,54.6,51.7$. HRMS (ESI) calcd for $\mathrm{C}_{26} \mathrm{H}_{24} \mathrm{BrN}_{2} \mathrm{O}_{4}[\mathrm{M}+\mathrm{H}]^{+}$507.0914, found 507.0918 .

3,4,5-Trimethoxy- $N$-(4-methylbenzyl)- $N$-(quinolin-8yl)benzamide (12d): White solid, yield 78\%. m.p. 127 $128{ }^{\circ} \mathrm{C} ;{ }^{1} \mathrm{H}$ NMR $\left(400 \mathrm{MHz}, \mathrm{CDCl}_{3}\right) \delta: 8.99$ (d, $J=2.8$ $\mathrm{Hz}, 1 \mathrm{H}), 8.09$ (d, $J=7.7 \mathrm{~Hz}, 1 \mathrm{H}), 7.57$ (d, $J=8.1 \mathrm{~Hz}, 1 \mathrm{H})$, 7.39 (dt, $J=27.2,13.6 \mathrm{~Hz}, 1 \mathrm{H}), 7.13$ (t, $J=7.5 \mathrm{~Hz}, 1 \mathrm{H})$, 7.05 (d, $J=7.9 \mathrm{~Hz}, 2 \mathrm{H}), 6.95$ (d, $J=7.8 \mathrm{~Hz}, 2 \mathrm{H}), 6.85$ (s, $1 \mathrm{H}), 6.49(\mathrm{~s}, 2 \mathrm{H}), 5.87(\mathrm{~s}, 1 \mathrm{H}), 4.56(\mathrm{~s}, 1 \mathrm{H}), 3.59(\mathrm{~s}, 3 \mathrm{H})$, $3.36(\mathrm{~d}, J=42.1 \mathrm{~Hz}, 6 \mathrm{H}), 2.21(\mathrm{~s}, 3 \mathrm{H}) ;{ }^{13} \mathrm{C}$ NMR $(100$ $\left.\mathrm{MHz}, \mathrm{CDCl}_{3}\right) \delta: 170.1,151.2,149.4,137.8,135.8,133.7$, 130.7, 128.2, 127.9, 126.7, 125.3, 120.6, 104.6, 59.7, 54.6, 51.9, 20.1; HRMS (ESI) calcd for $\mathrm{C}_{27} \mathrm{H}_{27} \mathrm{~N}_{2} \mathrm{O}_{4}[\mathrm{M}+\mathrm{H}]^{+}$ 443.1965, found 443.1972.

3,4,5-Trimethoxy- $N$-(4-methoxybenzyl)- $N$-(quinolin-8yl)benzamide (12e): White solid, yield 76\%. m.p. 125 $127{ }^{\circ} \mathrm{C} ;{ }^{1} \mathrm{H}$ NMR $\left(400 \mathrm{MHz}, \mathrm{CDCl}_{3}\right) \delta: 8.99$ (d, $J=2.9$ $\mathrm{Hz}, 1 \mathrm{H}), 8.09$ (d, $J=7.9 \mathrm{~Hz}, 1 \mathrm{H}), 7.57$ (d, $J=8.1 \mathrm{~Hz}, 1 \mathrm{H})$, 7.40 (dd, $J=8.1,4.1 \mathrm{~Hz}, 1 \mathrm{H}), 7.12(\mathrm{t}, J=7.7 \mathrm{~Hz}, 1 \mathrm{H}), 7.07$ $(\mathrm{d}, J=8.5 \mathrm{~Hz}, 2 \mathrm{H}), 6.81(\mathrm{~d}, J=6.0 \mathrm{~Hz}, 1 \mathrm{H}), 6.67(\mathrm{~d}, J=$ $8.6 \mathrm{~Hz}, 2 \mathrm{H}), 6.49(\mathrm{~s}, 2 \mathrm{H}), 5.84(\mathrm{~d}, J=11.7 \mathrm{~Hz}, 1 \mathrm{H}), 4.53$ (d, $J=13.2 \mathrm{~Hz}, 1 \mathrm{H}), 3.67$ (s, 3H), 3.59 (s, 3H), 3.30 (s, $6 \mathrm{H}) ;{ }^{13} \mathrm{C} \mathrm{NMR}\left(100 \mathrm{MHz}, \mathrm{CDCl}_{3}\right) \delta: 170.0,157.8,151.1$, $149.5,143.1,139.1,137.8,135.6,130.8,130.2,129.6$, $128.9,128.2,126.7,125.2,120.6,112.5,104.5,59.6,54.6$, 54.1, 51.5; HRMS (ESI) calcd for $\mathrm{C}_{27} \mathrm{H}_{27} \mathrm{~N}_{2} \mathrm{O}_{5}[\mathrm{M}+\mathrm{H}]^{+}$ 459.1914, found 459.1913.

$N$-(4-(tert-Butyl)benzyl)-3,4,5-trimethoxy- $N$-(quinolin8-yl)benzamide (12f): Yellow liquid, yield 58\%. ${ }^{1} \mathrm{H}$ NMR $\left(400 \mathrm{MHz}, \mathrm{CDCl}_{3}\right) \delta: 8.98(\mathrm{~s}, 1 \mathrm{H}), 8.10(\mathrm{~d}, J=7.3 \mathrm{~Hz}$, $1 \mathrm{H}), 7.59$ (d, $J=8.1 \mathrm{~Hz}, 1 \mathrm{H}), 7.46 \sim 7.33(\mathrm{~m}, 1 \mathrm{H}), 7.19$ (d, $J=2.7 \mathrm{~Hz}, 1 \mathrm{H}), 7.17(\mathrm{~s}, 2 \mathrm{H}), 7.11(\mathrm{~d}, J=8.2 \mathrm{~Hz}, 2 \mathrm{H}), 6.93$ $(\mathrm{s}, 1 \mathrm{H}), 6.52(\mathrm{~d}, J=8.3 \mathrm{~Hz}, 2 \mathrm{H}), 5.83(\mathrm{~s}, 1 \mathrm{H}), 4.59(\mathrm{~s}, 1 \mathrm{H})$, $3.60(\mathrm{~s}, 3 \mathrm{H}), 3.31(\mathrm{~s}, 6 \mathrm{H}), 1.20(\mathrm{~s}, 9 \mathrm{H}) ;{ }^{13} \mathrm{C}$ NMR $(100$ $\left.\mathrm{MHz}, \mathrm{CDCl}_{3}\right) \delta: 170.1,151.1,149.5,149.0,143.0,139.4$, $137.8,135.6,133.7,130.8,130.0,128.2,127.8,126.7$, 125.2, 124.1, 124.0, 120.6, 104.6, 59.6, 59.3, 54.6, 52.0, 33.4, 30.3, 20.0, 13.2; HRMS (ESI) calcd for $\mathrm{C}_{30} \mathrm{H}_{33} \mathrm{~N}_{2} \mathrm{O}_{4}$ $[\mathrm{M}+\mathrm{H}]^{+}$485.2435, found 485.2439.

$N$-(3-Fluorobenzyl)-3,4,5-trimethoxy- $N$-(quinolin-8-yl)benzamide (12g): White solid, yield 82\%. m.p. 135
$136{ }^{\circ} \mathrm{C} ;{ }^{1} \mathrm{H}$ NMR $\left(400 \mathrm{MHz}, \mathrm{CDCl}_{3}\right) \delta: 8.98(\mathrm{~d}, J=2.8$ $\mathrm{Hz}, 1 \mathrm{H}), 8.11(\mathrm{~d}, J=8.1 \mathrm{~Hz}, 1 \mathrm{H}), 7.60(\mathrm{~d}, J=8.1 \mathrm{~Hz}, 1 \mathrm{H})$, $7.41(\mathrm{dd}, J=8.2,4.1 \mathrm{~Hz}, 1 \mathrm{H}), 7.18 \sim 7.06(\mathrm{~m}, 2 \mathrm{H}), 7.02 \sim$ $6.88(\mathrm{~m}, 3 \mathrm{H}), 6.82(\mathrm{td}, J=8.4,2.2 \mathrm{~Hz}, 1 \mathrm{H}), 6.50(\mathrm{~s}, 2 \mathrm{H})$, $5.83(\mathrm{~d}, J=11.3 \mathrm{~Hz}, 1 \mathrm{H}), 4.67$ (d, $J=12.4 \mathrm{~Hz}, 1 \mathrm{H}), 3.60$ $(\mathrm{s}, 3 \mathrm{H}), 3.31(\mathrm{~s}, 6 \mathrm{H}) ;{ }^{13} \mathrm{C} \mathrm{NMR}\left(100 \mathrm{MHz}, \mathrm{CDCl}_{3}\right) \delta$ : $170.2,161.7$ (d, $J=244.0 \mathrm{~Hz}), 151.2,149.5,139.3$ (d, $J=$ $7.0 \mathrm{~Hz}), 138.0,135.7,130.3,129.9,128.6$ (d, $J=8.0 \mathrm{~Hz})$, $128.3,126.9,125.3,123.7$ (d, $J=3.0 \mathrm{~Hz}), 120.7,115.0$ (d, $J=210.0 \mathrm{~Hz}), 113.1(\mathrm{~d}, J=210.0 \mathrm{~Hz}), 104.6,59.7,54.6$, 51.9; HRMS (ESI) calcd for $\mathrm{C}_{26} \mathrm{H}_{24} \mathrm{FN}_{2} \mathrm{O}_{4}[\mathrm{M}+\mathrm{H}]$ 447.1715, found 447.1722 .

$N$-(3-Chlorobenzyl)-3,4,5-trimethoxy- $N$-(quinolin-8-yl)benzamide (12h): White solid, yield 80\%. m.p. 141 $142{ }^{\circ} \mathrm{C} ;{ }^{1} \mathrm{H}$ NMR (400 MHz, $\left.\mathrm{CDCl}_{3}\right) \delta: 8.98$ (d, $J=2.8$ $\mathrm{Hz}, 1 \mathrm{H}), 8.11(\mathrm{~d}, J=8.0 \mathrm{~Hz}, 1 \mathrm{H}), 7.60(\mathrm{~d}, J=8.1 \mathrm{~Hz}, 1 \mathrm{H})$, 7.41 (dd, $J=8.2,4.1 \mathrm{~Hz}, 1 \mathrm{H}), 7.22$ (s, 1H), 7.16 (d, $J=7.7$ $\mathrm{Hz}, 1 \mathrm{H}), 7.13 \sim 7.05(\mathrm{~m}, 3 \mathrm{H}), 6.91(\mathrm{~d}, J=6.6 \mathrm{~Hz}, 1 \mathrm{H})$, $6.50(\mathrm{~s}, 2 \mathrm{H}), 5.78(\mathrm{~s}, 1 \mathrm{H}), 4.66(\mathrm{~d}, J=11.6 \mathrm{~Hz}, 1 \mathrm{H}), 3.60$ $(\mathrm{s}, 3 \mathrm{H}), 3.31(\mathrm{~s}, 6 \mathrm{H}) ;{ }^{13} \mathrm{C} \mathrm{NMR}\left(100 \mathrm{MHz}, \mathrm{CDCl}_{3}\right) \delta$ : $170.2,151.2,149.5,138.8,138.0,135.7,133.0,130.3$, $129.9,128.5,128.3,128.2,126.9,126.5,126.3,125.3$, 120.7, 104.6, 59.7, 54.6, 51.8; HRMS (ESI) calcd for $\mathrm{C}_{26} \mathrm{H}_{24} \mathrm{ClN}_{2} \mathrm{O}_{4}[\mathrm{M}+\mathrm{H}]^{+}$463.1419, found 463.1424.

3,4,5-Trimethoxy- $N$-(3-methylbenzyl)- $N$-(quinolin-8yl)benzamide (12i): White solid, yield 67\%. m.p. 127 $128{ }^{\circ} \mathrm{C} ;{ }^{1} \mathrm{H}$ NMR (400 MHz, $\left.\mathrm{CDCl}_{3}\right) \delta: 8.98$ (d, $J=2.7$ $\mathrm{Hz}, 1 \mathrm{H}), 8.08$ (d, $J=8.1 \mathrm{~Hz}, 1 \mathrm{H}), 7.57$ (d, $J=8.0 \mathrm{~Hz}, 1 \mathrm{H})$, $7.39(\mathrm{dd}, J=8.2,4.2 \mathrm{~Hz}, 1 \mathrm{H}), 7.13(\mathrm{t}, J=7.7 \mathrm{~Hz}, 1 \mathrm{H})$, $7.06 \sim 7.00(\mathrm{~m}, 2 \mathrm{H}), 6.94(\mathrm{~d}, J=7.5 \mathrm{~Hz}, 2 \mathrm{H}), 6.89$ (d, $J=$ $6.5 \mathrm{~Hz}, 1 \mathrm{H}), 6.50(\mathrm{~s}, 2 \mathrm{H}), 5.88$ (d, $J=10.8 \mathrm{~Hz}, 1 \mathrm{H}), 4.57$ $(\mathrm{d}, J=12.1 \mathrm{~Hz}, 1 \mathrm{H}), 3.59$ (s, 3H), $3.31(\mathrm{~s}, 6 \mathrm{H}), 2.19$ (s, $3 \mathrm{H}) ;{ }^{13} \mathrm{C}$ NMR $\left(100 \mathrm{MHz}, \mathrm{CDCl}_{3}\right) \delta: 170.1,151.1,149.4$, $143.0,139.3,137.8,136.8,136.6,135.5,130.8,130.0$, $128.9,128.2,127.0,127.0,126.7,125.2,120.6,104.5$, 59.6, 54.6, 52.2, 20.3; HRMS (ESI) calcd for $\mathrm{C}_{27} \mathrm{H}_{27} \mathrm{~N}_{2} \mathrm{O}_{4}$ $[\mathrm{M}+\mathrm{H}]^{+}$443.1965, found 443.1971.

$N$-(3-(Chloromethyl)benzyl)-3,4,5-trimethoxy- $N$-(quinolin-8-yl)benzamide (12j): White solid, yield 65\%. m.p. $130 \sim 132{ }^{\circ} \mathrm{C} ;{ }^{1} \mathrm{H}$ NMR $\left(400 \mathrm{MHz}, \mathrm{CDCl}_{3}\right) \delta: 8.98(\mathrm{~d}, J=$ $2.8 \mathrm{~Hz}, 1 \mathrm{H}), 8.10(\mathrm{~d}, J=7.8 \mathrm{~Hz}, 1 \mathrm{H}), 7.59(\mathrm{~d}, J=8.1 \mathrm{~Hz}$, $1 \mathrm{H}), 7.40(\mathrm{dd}, J=8.1,4.1 \mathrm{~Hz}, 1 \mathrm{H}), 7.20(\mathrm{~d}, J=1.1 \mathrm{~Hz}$, $1 \mathrm{H}), 7.15(\mathrm{t}, J=6.1 \mathrm{~Hz}, 4 \mathrm{H}), 6.89(\mathrm{~d}, J=6.0 \mathrm{~Hz}, 1 \mathrm{H}), 6.51$ $(\mathrm{s}, 2 \mathrm{H}), 5.85(\mathrm{~d}, J=12.3 \mathrm{~Hz}, 1 \mathrm{H}), 4.79 \sim 4.52(\mathrm{~m}, 1 \mathrm{H})$, $4.43(\mathrm{~s}, 2 \mathrm{H}), 3.60(\mathrm{~s}, 3 \mathrm{H}), 3.31(\mathrm{~s}, 6 \mathrm{H}) ;{ }^{13} \mathrm{C}$ NMR $(100$ $\left.\mathrm{MHz}, \mathrm{CDCl}_{3}\right) \delta: 170.2,151.2,149.5,139.1,137.9,137.3$, $136.4,135.6,130.5,129.9,128.4,128.3,127.6,126.8$, $126.5,125.3,120.6,104.6,59.7,54.6,52.0,45.2$. HRMS (ESI) calcd for $\mathrm{C}_{27} \mathrm{H}_{26} \mathrm{ClN}_{2} \mathrm{O}_{4}[\mathrm{M}+\mathrm{H}]^{+}$477.1576, found 477.1583.

$N$-(2,4-Dichlorobenzyl)-3,4,5-trimethoxy- $N$-(quinolin-8yl)benzamide (12k): White solid, yield 68\%. m.p. 137 $138{ }^{\circ} \mathrm{C} ;{ }^{1} \mathrm{H}$ NMR $\left(400 \mathrm{MHz}, \mathrm{CDCl}_{3}\right) \delta: 8.95$ (d, $J=2.7$ $\mathrm{Hz}, 1 \mathrm{H}), 8.07$ (d, $J=8.1 \mathrm{~Hz}, 1 \mathrm{H}), 7.65$ (d, $J=8.1 \mathrm{~Hz}, 1 \mathrm{H})$, $7.59(\mathrm{~d}, J=8.1 \mathrm{~Hz}, 1 \mathrm{H}), 7.38(\mathrm{dd}, J=8.3,4.2 \mathrm{~Hz}, 1 \mathrm{H})$, 7.15 (ddd, $J=12.2,10.7,2.7 \mathrm{~Hz}, 3 \mathrm{H}), 6.96(\mathrm{t}, J=14.0 \mathrm{~Hz}$, $1 \mathrm{H}), 6.51(\mathrm{~s}, 2 \mathrm{H}), 5.71(\mathrm{~s}, 1 \mathrm{H}), 5.04(\mathrm{~s}, 1 \mathrm{H}), 3.60(\mathrm{~s}, 3 \mathrm{H})$, 
$3.33(\mathrm{~s}, 6 \mathrm{H}) ;{ }^{13} \mathrm{C} \mathrm{NMR}\left(100 \mathrm{MHz}, \mathrm{CDCl}_{3}\right) \delta: 170.3,151.2$, $149.5,143.2,139.1,138.0,135.5,133.7,133.0,132.5$, $131.1,130.3,129.1,128.2,127.9,127.0,126.2,125.2$, 120.7, 104.6, 59.7, 54.6, 48.9; HRMS (ESI) calcd for $\mathrm{C}_{26} \mathrm{H}_{23} \mathrm{Cl}_{2} \mathrm{~N}_{2} \mathrm{O}_{4}[\mathrm{M}+\mathrm{H}]^{+}$497.1029, found 497.1034.

3,4,5-Trimethoxy- $N$-((4-methylquinazolin-2-yl)methyl)$N$-(quinolin-8-yl)benzamide (12l): White solid, yield $62 \%$. m.p. $157 \sim 158{ }^{\circ} \mathrm{C} ;{ }^{1} \mathrm{H}$ NMR (400 $\left.\mathrm{MHz}, \mathrm{CDCl}_{3}\right) \delta: 8.97$ $(\mathrm{dd}, J=4.2,1.6 \mathrm{~Hz}, 1 \mathrm{H}), 8.06(\mathrm{dd}, J=8.3,1.5 \mathrm{~Hz}, 1 \mathrm{H})$, $7.95(\mathrm{~d}, J=8.0 \mathrm{~Hz}, 1 \mathrm{H}), 7.90(\mathrm{~d}, J=8.4 \mathrm{~Hz}, 1 \mathrm{H}), 7.81$ (d, $J=7.3 \mathrm{~Hz}, 1 \mathrm{H}), 7.78 \sim 7.70(\mathrm{~m}, 1 \mathrm{H}), 7.56(\mathrm{~d}, J=8.0 \mathrm{~Hz}$, $1 \mathrm{H}), 7.48(\mathrm{t}, J=7.3 \mathrm{~Hz}, 1 \mathrm{H}), 7.36(\mathrm{dd}, J=8.3,4.2 \mathrm{~Hz}$, $1 \mathrm{H}), 7.23$ (t, $J=7.8 \mathrm{~Hz}, 1 \mathrm{H}), 6.60(\mathrm{~s}, 2 \mathrm{H}), 6.15(\mathrm{~s}, 1 \mathrm{H})$, $5.12(\mathrm{~d}, J=14.1 \mathrm{~Hz}, 1 \mathrm{H}), 3.63$ (s, 3H), 3.34 (s, 6H), 2.83 $(\mathrm{s}, 3 \mathrm{H}) ;{ }^{13} \mathrm{C}$ NMR $\left(100 \mathrm{MHz}, \mathrm{CDCl}_{3}\right) \delta: 170.4,167.3$, $161.3,151.2,149.5,148.9,143.2,140.3,137.8,135.3$, $132.4,130.8,130.7,128.1,127.8,126.4,125.8,125.2$, 123.9, 122.0, 120.4, 104.8, 59.7, 54.6, 20.8; HRMS (ESI) calcd for $\mathrm{C}_{29} \mathrm{H}_{27} \mathrm{~N}_{4} \mathrm{O}_{4}[\mathrm{M}+\mathrm{H}]^{+}$495.2027, found 495.2031 .

$N$-((1H-Benzo[d]imidazol-2-yl)methyl)-3,4,5-trimethoxy- $N$-(quinolin-8-yl)benzamide (12m): White solid, yield 61\%. m.p. 104 105 ${ }^{\circ} \mathrm{C}$; ${ }^{1} \mathrm{H}$ NMR (400 MHz, DMSO- $d_{6}$ ) $\delta: 12.95(\mathrm{~s}, 1 \mathrm{H}), 9.00 \sim 8.87(\mathrm{~m}, 1 \mathrm{H}), 8.48 \sim 8.32(\mathrm{~m}, 1 \mathrm{H})$, 7.89 (d, $J=8.2 \mathrm{~Hz}, 1 \mathrm{H}), 7.74(\mathrm{dd}, J=20.2,7.6 \mathrm{~Hz}, 1 \mathrm{H})$, $7.61 \sim 7.54(\mathrm{~m}, 1 \mathrm{H}), 7.52 \sim 7.45(\mathrm{~m}, 1 \mathrm{H}), 7.30(\mathrm{dd}, J=$ $15.8,8.1 \mathrm{~Hz}, 1 \mathrm{H}), 7.24(\mathrm{~s}, 2 \mathrm{H}), 7.02$ (d, $J=8.4 \mathrm{~Hz}, 2 \mathrm{H})$, $6.43(\mathrm{~s}, 1 \mathrm{H}), 5.82(\mathrm{~s}, 1 \mathrm{H}), 5.12(\mathrm{~s}, 1 \mathrm{H}), 3.71(\mathrm{~d}, J=17.3$ $\mathrm{Hz}, 6 \mathrm{H}), 3.49$ (s, 3H); ${ }^{13} \mathrm{C}$ NMR (100 MHz, DMSO-d $\left.d_{6}\right) \delta$ : $166.9,152.9,152.6,151.7,150.8,143.4,141.9,141.4$, $138.3,136.6,133.8,130.9,128.7,128.1,127.9,126.3$, $125.9,124.0,121.9,119.6,113.4,107.5,106.5,105.2$, 60.4, 60.1, 59.9, 56.1, 55.9, 55.2; HRMS (ESI) calcd for $\mathrm{C}_{27} \mathrm{H}_{25} \mathrm{~N}_{4} \mathrm{O}_{4}[\mathrm{M}+\mathrm{H}]^{+}$469.1870, found 469.1874.

$N$-((5-Chlorobenzo[b]thiophen-3-yl)methyl)-3,4,5-trimethoxy- $N$-(quinolin-8-yl)benzamide (12n): White solid, yield 43\%. m.p. $174 \sim 175{ }^{\circ} \mathrm{C} ;{ }^{1} \mathrm{H}$ NMR $(400 \mathrm{MHz}$, $\left.\mathrm{CDCl}_{3}\right) \delta: 8.99(\mathrm{dd}, J=4.1,1.5 \mathrm{~Hz}, 1 \mathrm{H}), 8.09$ (d, $J=7.3$ $\mathrm{Hz}, 1 \mathrm{H}), 7.59$ (d, $J=8.5 \mathrm{~Hz}, 1 \mathrm{H}), 7.55$ (d, $J=8.0 \mathrm{~Hz}, 1 \mathrm{H})$, $7.50(\mathrm{~d}, J=1.7 \mathrm{~Hz}, 1 \mathrm{H}), 7.41(\mathrm{dd}, J=8.3,4.2 \mathrm{~Hz}, 1 \mathrm{H})$, 7.19 (s, 1H), 7.15 (dd, $J=8.6,1.8 \mathrm{~Hz}, 1 \mathrm{H}), 7.02$ (t, $J=7.8$ $\mathrm{Hz}, 1 \mathrm{H}), 6.73(\mathrm{~d}, J=6.9 \mathrm{~Hz}, 1 \mathrm{H}), 6.50(\mathrm{~s}, 2 \mathrm{H}), 6.01(\mathrm{~d}, J=$ $13.5 \mathrm{~Hz}, 1 \mathrm{H}), 4.95$ (d, $J=13.9 \mathrm{~Hz}, 1 \mathrm{H}), 3.59$ (s, 3H), 3.31 $(\mathrm{s}, 6 \mathrm{H}) ;{ }^{13} \mathrm{C} \mathrm{NMR}\left(100 \mathrm{MHz}, \mathrm{CDCl}_{3}\right) \delta: 170.1,151.2$, $149.7,143.1,138.9,138.7,137.9,137.2,135.6,131.2$, $130.5,129.7,129.4,128.2,127.1,127.0,125.1,123.6$, 122.5, 121.0, 120.7, 104.5, 59.7, 54.6, 45.0; HRMS (ESI) calcd for $\mathrm{C}_{28} \mathrm{H}_{24} \mathrm{ClN}_{2} \mathrm{O}_{4} \mathrm{~S}[\mathrm{M}+\mathrm{H}]^{+}$519.1140, found 519.1146.

$N$-((5-Chlorothiophen-2-yl)methyl)-3,4,5-trimethoxy- $N$ (quinolin-8-yl)benzamide (12o): White solid, yield 52\%. m.p. $168 \sim 169{ }^{\circ} \mathrm{C} ;{ }^{1} \mathrm{H}$ NMR $\left(400 \mathrm{MHz}, \mathrm{CDCl}_{3}\right) \delta: 9.00$ $(\mathrm{dd}, J=4.1,1.6 \mathrm{~Hz}, 1 \mathrm{H}), 8.19 \sim 8.08(\mathrm{~m}, 1 \mathrm{H}), 7.63(\mathrm{~d}, J=$ $8.2 \mathrm{~Hz}, 1 \mathrm{H}), 7.43(\mathrm{dd}, J=8.3,4.2 \mathrm{~Hz}, 1 \mathrm{H}), 7.19$ (dd, $J=$ 9.1, $6.4 \mathrm{~Hz}, 1 \mathrm{H}), 6.92(\mathrm{~d}, J=7.2 \mathrm{~Hz}, 1 \mathrm{H}), 6.55$ (d, $J=3.7$ $\mathrm{Hz}, 1 \mathrm{H}), 6.49$ (s, 2H), 6.38 (d, $J=3.7 \mathrm{~Hz}, 1 \mathrm{H}), 5.74$ (d, $J=$ $14.7 \mathrm{~Hz}, 1 \mathrm{H}), 4.73$ (d, $J=14.7 \mathrm{~Hz}, 1 \mathrm{H}), 3.61$ (s, 3H), 3.29 $(\mathrm{s}, 6 \mathrm{H}) ;{ }^{13} \mathrm{C}$ NMR $\left(100 \mathrm{MHz}, \mathrm{CDCl}_{3}\right) \delta: 170.0,151.2$, $149.7,142.8,138.6,138.2,137.7,135.7,130.1,129.8$, $129.0,128.3,127.0,126.0,125.5,124.1,120.8,104.7$, 59.7, 54.6, 47.6; HRMS (ESI) calcd for $\mathrm{C}_{24} \mathrm{H}_{22} \mathrm{ClN}_{2} \mathrm{O}_{4} \mathrm{~S}$ $[\mathrm{M}+\mathrm{H}]^{+}$469.0983, found 469.0988.

\subsection{In vitro antitumor activities}

\subsubsection{Cell culture and cell viability assay}

EC-109 cells (Human esophageal cancer cells), PC-3 cells (human prostate cancer) and MGC-803 cells (human gastric cancer) were cultured at $37{ }^{\circ} \mathrm{C}$ in an atmosphere containing 5\% $\mathrm{CO}_{2}$, RPMI-1640 medium with $10 \%$ fetal bovine serum, $100 \mathrm{U} / \mathrm{mL}$ penicillin and $0.1 \mathrm{mg} / \mathrm{mL}$ streptomycin was used as culture medium. In cell viability assay, cells were seeded at a density of $5 \times 10^{3}$ per well in 96-well plates and treated with compounds for $48 \mathrm{~h}$ after $24 \mathrm{~h}$ incubation. Then, $20 \mu \mathrm{L}$ MTT solution each well was added, and incubated for $4 \mathrm{~h}$ at $37{ }^{\circ} \mathrm{C} .100 \mu \mathrm{L}$ of DMSO was added to each well to dissolve formazan after removing the supernatant liquid, the absorbance was determined at $570 \mathrm{~nm}$.

\subsubsection{Colony formatting assay}

PC-3 cells were seeded in a 6-well plate and incubated in $5 \% \mathrm{CO}_{2}$ at $37{ }^{\circ} \mathrm{C}$ for $24 \mathrm{~h}$, then treated with different concentration of compound. After $7 \mathrm{~d}$, we remove the culture medium, wash the cells 3 times with PBS, then cells were fixed with 4\% paraformaldehyde and stained with $0.1 \%$ crystal violet. The cells images were captured with microscope (Nikon, Japan).

\subsubsection{Cell cycle distribution assay}

PC-3 cells were seeded in 6-well culture plate and treated with compound for $48 \mathrm{~h}$. Then cells were harvested and fixed with $70 \%$ ethanol for $8 \mathrm{~h}$ at $4{ }^{\circ} \mathrm{C}$. The fixed cells were washed and resuspended using PBS containing 50 $\mathrm{mg} / \mathrm{mL}$ and PI $10 \mathrm{mg} / \mathrm{mL}$ RNaseA. Then cell suspension was incubated for $40 \mathrm{~min}$ in a dark place at room temperature. After that, samples were analyzed for DNA content with flow cytometry (Becton, Dickinson and Company, $\mathrm{NJ})$.

\subsubsection{Cell apoptosis assay}

PC-3 cells were seeded in 6-well culture plate and treated with compound for $48 \mathrm{~h}$. Then cells were harvested and resuspended in binding buffer containing $0.5 \mathrm{mg} / \mathrm{mL}$ Annexin V-FITC and $0.5 \mathrm{mg} / \mathrm{mL} \mathrm{PI}$, then incubated for 40 min in a dark place. After that, samples were analyzed with flow cytometry (Becton, Dickinson and Company, NJ)

\subsubsection{Western blotting analysis}

PC-3 cells treated with different concentration of compound were harvested and lysed. Protein lysates were denatured and resolved by SDS-PAGE, then transferred to nitrocellulose membrane. The membranes were incubated with appropriate antibodies overnight at $4{ }^{\circ} \mathrm{C}$ after blocking with 5\% skimmed milk. After conjugated with secondary antibodies, the detection of proteins was carried out with an ECL kit. 


\subsubsection{Statistical analysis}

Data from three independent experiments are presented as mean $\pm \mathrm{SD}$. $\mathrm{IC}_{50}$ values and $\mathrm{SD}$ values were calculated by SPSS version 10.0 (SPSS, Inc, Chicago, IL, USA).

Supporting Information The experimental procedure, NMR and ESI-MS of the compounds. The Supporting Information is available free of charge via the Internet at http://sioc-journal.cn.

\section{References}

[1] Bray, F.; Ferlay, J.; Soerjomataram, I.; Siegel, R. L.; Torre, L. A.; Jemal, A. Ca-Cancer J. Clin. 2018, 68, 394.

[2] Zhu, S.-L.; Wu, Y.; Liu, C.-J.; Wei, C.-Y.; Tao, J.-C.; Liu, H.-M. Eur. J. Med. Chem. 2013, 65, 70 .

[3] Saraswati, A. P.; Relitti, N.; Brindisi, M.; Gemma, S.; Zisterer, D.; Butini, S.; Campiani, G. Drug Discovery Today 2019, 24, 1370.

[4] Afzal, O.; Kumar, S.; Haider, M. R.; Ali, M. R.; Kumar, R.; Jaggi, M.; Bawa, S. Eur. J. Med. Chem. 2015, 97, 871.

[5] Hamdy, R.; Elseginy, S.; Ziedan, N.; Jones, A.; Westwell, A. Molecules 2019, 24, 1274.

[6] Mrozek-Wilczkiewicz, A.; Malarz, K.; Rejmund, M.; Polanski, J.; Musiol, R. Eur. J. Med. Chem. 2019, 171, 180.

[7] Shen, C.; Xu, J.; Xia, C.; Yang, Y.; Shen, H.; Ying, B.; Zhu, X. Zhang, P. Science 2018, 360, 20.

[8] El-Gamal, K. M.; El-Morsy, A. M.; Saad, A. M.; Eissa, I. H.; Alswah, M. J. Mol. Struct. 2018, 1166, 15.

[9] Akash, B.; Yasmeen, A.; Young, S. K.; Verrill, M. N.; Shouguang, J.; Robert, W. H. Eur. J. Med. Chem. 2018, 155, 705.

[10] Pankaj, W.; Priti, J.; Santosh, R.; Hemant, R. A. J. Curr. Drug Discovery Technol. 2018, 15, 2.

[11] Chokkar, N.; Kalra, S.; Chauhan, M.; Kumar, R. Mini-Rev. Med. Chem. 2019, 19, 510.

[12] Hosseinzadeh, H.; Mazaheri, F.; Ghodsi, R. Iran J. Basic Med. Sci. 2017, 20, 446 .

[13] Han, B.; Li, K.; Zhao, Y.; Li, B.; Cheng, Y.; Zhou, J.; Lu, Y.; Shi, Y.; Wang, Z.; Jiang, L. Br. J. Cancer 2018, 118, 654.

[14] Vaishampayan, U. N.; Podgorski, I.; Heilbrun, L. K.; LawhornCrews, J. M.; Dobson, K. C.; Boerner, J.; Stark, K.; Smith, D. W.; Heath, E. I.; Fontana, J. A. Clin. Cancer Res. 2019, 25, 652.

[15] Zhu, X.-F.; Zhang, J.; Sun, S.; Guo, Y.-C.; Cao, S.-X.; Zhao, Y.-F. Chin. Chem. Lett. 2017, 28, 1514.
[16] Yang, H.; Qi, H.; Liu, T.; Shao, X.; Yang, Q.; Qian, X. Chin. Chem. Lett. 2019, 30, 977.

[17] Yang, Y.; Guo, J.; Liu, Z.-Z. Chin. J. Org. Chem. 2019, 39, 1913 (in Chinese). (杨扬，郭举，刘站柱，有机化学, 2019, 39, 1913.)

[18] Hu, Y.; Li, Z.-Y.; Ding, Y.-J.; Li, Z.-Y.; Shen, Y.-M. Chin. J. Org. Chem. 2019, 39, 3230 (in Chinese) (胡园，李震宇，丁艳娇，李志颖，刘志勇，沈月毛，有机化学， 2019, 39, 3230.)

[19] Li, Z.-Y.; Ding, Y.-J.; Bu, H.-G.; Shen, Y.-M. Chin. J. Org. Chem. 2018, 38, 3204 (in Chinese). (李志颖，丁艳娇，卜华港，沈月毛，有机化学, 2018, 38, 3204.)

[20] Okten, S.; Cakmak, O.; Tekin, S.; Koprulu, T. K. Lett. Drug Des. Discovery 2017, 14, 1415.

[21] Yang, W.; Dolloff, N. G.; El-Deiry, W. S. Nat. Cell Biol. 2008, 10, 125.

[22] Ganesh, T.; Min, J.; Thepchatri, P.; Du, Y.; Li, L.; Lewis, I.; Wilson, L.; Fu, H.; Chiosis, G.; Dingledine, R. Bioorg. Med. Chem. Lett. 2008, 16, 6903.

[23] Lo, Y.-H.; Lin, Y.-T.; Liu, Y.-P.; Duh, T.-H.; Lu, P.-J.; Wu, M.-J. Eur. J. Med. Chem. 2013, 62, 526.

[24] Pingaew, R.; Saekee, A.; Mandi, P.; Nantasenamat, C.; Prachayasittikul, S.; Ruchirawat, S.; Prachayasittikul, V. Eur. J. Med. Chem. 2014, 85,65 .

[25] Romagnoli, R.; Baraldi, P. G.; Kimatrai Salvador, M.; Preti, D.; Aghazadeh Tabrizi, M.; Bassetto, M.; Brancale, A.; Hamel, E.; Castagliuolo, I.; Bortolozzi, R. J. Med. Chem. 2013, 56, 2606.

[26] Vitale, I.; Antoccia, A.; Cenciarelli, C.; Crateri, P.; Meschini, S.; Arancia, G.; Pisano, C.; Tanzarella, C. Apoptosis 2007, 12, 155.

[27] Wang, L.; Liu, S.; Wang, L.; Yan, P.; Wang, J.; Zhang, J.; Guo, H.; Guan, Q.; Bao, K.; Wu,Y. Eur. J. Med. Chem. 2018, 156, 137.

[28] Yan, J.; Chen, J.; Zhang, S.; Hu, J.; Huang, L.; Li, X. J. Med. Chem. 2016, 59, 5264.

[29] ElHady, A. K.; Abdel-Halim, M.; Abadi, A. H.; Engel, M. J. Med. Chem. 2017, 60, 5377.

[30] Hammill, J. T.; Bhasin, D.; Scott, D. C.; Min, J.; Chen, Y.; Lu, Y.; Yang, L.; Kim, H. S.; Connelly, M. C.; Hammill, C. J. Med. Chem. 2018, 61, 2694.

[31] Fu, D.-J.; Fu, L.; Liu, Y.-C.; Wang, J.-W.; Wang, Y.-Q.; Han, B.-K.; Li, X.-R.; Zhang, C.; Li, F.; Song, J. Sci. Rep. 2017, 7, 12788.

[32] Fu, D.-J.; Li, P.; Wu, B.-W.; Cui, X.-X.; Zhao, C.-B.; Zhang, S.-Y. Eur. J. Med. Chem. 2019, 165, 309.

[33] Fu, D.-J.; Yang, J.-J.; Li, P.; Hou, Y.-H.; Huang, S.-N.; Tippin, M. A.; Pham, V.; Song, L.; Zi, X.; Xue, W.-L. Eur. J. Med. Chem. 2018, 157,50 . 